\title{
Generalized Trust, External Sourcing, and Firm Performance in Economic Downturns
}

\author{
Bart S. Vanneste, ${ }^{a}$ Ranjay Gulati ${ }^{b}$ \\ ${ }^{\mathbf{a}}$ UCL School of Management, University College London, London E14 5AA, United Kingdom; ${ }^{\mathbf{b}}$ Harvard Business School, Harvard \\ University, Boston, Massachusetts 02163 \\ Contact: b.vanneste@ucl.ac.uk, iD https://orcid.org/0000-0002-3209-9370 (BSV); rgulati@hbs.edu, iD https://orcid.org/0000-0002-0986-234X \\ (RG)
}

Received: August 24, 2018

Revised: October 5, 2020; March 9, 2021; May 11, 2021

Accepted: May 16, 2021

Published Online in Articles in Advance:

September 7, 2021

https://doi.org/10.1287/orsc.2021.1500

Copyright: (c) 2021 The Author(s)

\begin{abstract}
Going beyond prior research that has focused on dyadic, party-specific trust, this study investigates the importance of generalized trust, which is not specific to a counterparty and originates from a broader context. We analyze how generalized trust at the regional level affects the extent to which a firm relies on external suppliers and the performance effects of doing so. Furthermore, we assess how these relationships are impacted by an economic downturn. We exploit differences in generalized trust across 145 regions in 12 European countries and use data on more than a million small- and medium-sized enterprises (SMEs) before and during the Great Financial Crisis (from 2008 to 2010). Control variables are selected via a double-selection procedure based on machine learning. We find that firms in high generalized trust regions, compared with those in low generalized trust regions, source more externally (but do not reduce external sourcing less in an economic downturn) and benefit more from external sourcing during an economic downturn.

Open Access Statement: This work is licensed under a Creative Commons Attribution-ShareAlike 4.0 International License. You are free to download this work and share with others for any purpose, even commercially if you distribute your contributions under the same license as the original, and you must attribute this work as "Organization Science. Copyright @ 2021 The Author(s). https://doi. org/10.1287/orsc.2021.1500, used under a Creative Commons Attribution License: https:// creativecommons.org/licenses/by-sa/4.0/."

Supplemental Material: The online appendix is available at https://doi.org/10.1287/orsc.2021.1500.
\end{abstract}

Keywords: generalized trust • trust • interorganizational relationships • strategic alliances • partnerships • external sourcing • economic downturn - Great Financial Crisis • small- and medium-sized enterprises (SMEs) • regional studies • machine learning

\section{Introduction}

Relationships between firms are an important unit of analysis for understanding how value is created and captured (Gulati 1995a, Dyer and Singh 1998). Indeed, many firms obtain most of their inputs from other firms (Van Weele 2014), and trust is considered important for managing these relationships (Gulati 1995b, Zaheer and Venkatraman 1995, Sako and Helper 1998, Zaheer et al. 1998, Dyer et al. 2018, Vanneste and Yoo 2020). Hence, many studies have investigated the role of trust in relationships between firms and its performance consequences (for metaanalyses, see Cao and Lumineau 2015, Krishnan et al. 2016, and Connelly et al. 2018). Dyadic trust not only shapes the nature of interactions between firms, but it can also increase the propensity of firms to enter new partnerships in the first place (Gulati 1999). Regardless, in these studies, trust is dyadic and encompasses the trust one has in a specific other.

However, trust can also be generalized (Putnam 1993, Fukuyama 1995). Generalized trust is the trust one has in an unknown other (Nannestad 2008). Many studies have documented substantial differences in generalized trust between countries (Nannestad 2008, Algan and Cahuc 2013) and also between regions within the same country (Tabellini 2010). Consider, for example, Galicia and Castilla y León-two neighboring regions in the northwest region of Spain. In surveys measuring generalized trust, respondents' scores were $50 \%$ higher in Castilla y León than in Galicia. Furthermore, generalized trust is remarkably stable over time; therefore, we may expect the trust difference between Galicia and Castilla y León to persist (Uslaner 2002, Bjørnskov 2007).

In the present study, we explore whether and how variations in generalized trust between regions shape the behavior and performance of firms in those regions. Consider Alpha and Beta, fictitious names for two real-world firms in our sample. Both produce wooden furniture, and each has annual sales of about EUR 1 million. However, Beta obtains $80 \%$ of its volume of inputs from other firms, whereas Alpha obtains only $65 \%$. What accounts for this difference? We systematically explore the explanation that Alpha is 
located in Galicia, a region with below-average generalized trust, whereas Beta is in Castilla y León, a region with above-average generalized trust. We also investigate whether the degree of external sourcing has a differential effect on firm performance depending on the level of generalized trust in the region where the firm is based.

We seek not only to explore the possible role of generalized trust in shaping organizational behavior and performance, but also to uncover some of the likely mechanisms underlying its effects. With that aim, we explore the role of generalized trust before and during an economic downturn, when relationships are at risk for being terminated. Considering the time before and during the Great Financial Crisis (from 2008 to 2010), we analyze how firms in high versus low generalized trust regions differ in terms of external sourcing and its consequences on performance.

Focusing on generalized trust allows us to address two facets of trust, which are not easily accounted for when considering only dyadic trust. First, the consequences of generalized trust extend beyond a single exchange partner and affect the entire array of relationships in which a firm may be placed. This, in turn, allows us to study a firm's portfolio of relationships by considering its degree of external sourcing. Second, generalized trust differs between regions, which gives us an opportunity to understand why firms' behavior and performance differ across regions.

We test our theory by exploiting differences in generalized trust between regions within the same country. To obtain firms located in a single region, we focus on small- and medium-sized enterprises (SMEs). Their external suppliers need not be located in the same region. The data consist of more than a million SMEs from 145 regions in 12 European countries: the Czech Republic, Denmark, France, Germany, Hungary, Italy, Poland, Portugal, Romania, Slovakia, Spain, and the United Kingdom.

The present study makes two main contributions. First, the literature on interorganizational relationships and trust has extensively studied dyadic trust, which is specific to another party (for a meta-analysis, see Connelly et al. 2018). The present study extends this literature by considering trust that is not specific to another party-in other words, generalized trust. Focusing on generalized trust allows us to explore a source of trust that remains underresearched in prior research on interorganizational relationships, as well as augment the literature by focusing on a distinct level of analysis: the geographic area in which a firm is located.

Second, the literature on governance modes (or the organization of economic activity) and trust has prioritized studying the effect of trust in a single, rather than multiple, governance mode (i.e., looking at either interorganizational or intraorganizational relationships, but not both). In contrast, we analyze a firm's portfolio of relationships, which includes both interorganizational and intraorganizational relationships. For example, many studies have investigated trust's performance implications by comparing low-trust with high-trust interorganizational relationships (for reviews, see Cao and Lumineau 2015, Krishnan et al. 2016, and Connelly et al. 2018) or low-trust with hightrust intraorganizational relationships (for reviews, see Dirks and Ferrin 2002, Colquitt et al. 2007, and De Jong et al. 2016). Almost no research has compared within-firm relationships directly with between-firm relationships (an exception is Gulati and Nickerson 2008, who focus on dyadic trust). Research has similarly focused on how trust affects the choice either of relational and contractual approaches between firms (Gulati 1995b, Poppo and Zenger 2002, Puranam and Vanneste 2009; for reviews, see Cao and Lumineau 2015 and Krishnan et al. 2016) or of decentralization within firms (Bloom et al. 2012). The present study investigates a firm's degree of external sourcing, or the extent to which it relies on external versus internal parties. Hence, we seek to understand how generalized trust affects the choice of internal (within-firm) versus external (between-firms) sourcing and the firm performance consequences of doing so.

\section{Theory \\ Background}

This study explores how trust shapes a firm's behavior and affects its performance. Prior research has dealt with specific trust, defined as "the willingness of a party to be vulnerable to the actions of another party based on the expectation that the other will perform a particular action important to the trustor, irrespective of the ability to monitor or control that other party" (Mayer et al. 1995, p. 712). Researchers have argued that trust can lower transaction costs between contracting parties (Arrow 1974, Bradach and Eccles 1989, Kramer 1999). Numerous studies have documented that trust is linked to superior performance when parties transact either within firms (for meta-analyses, see Dirks and Ferrin 2002, Colquitt et al. 2007, and De Jong et al. 2016) or between firms (for meta-analyses, see Cao and Lumineau 2015, Krishnan et al. 2016, and Connelly et al. 2018). In most of the research in this field, trust is both conceptualized and measured at a dyadic level - that is, as a willingness to be vulnerable to a specific counterparty.

Much less research has investigated generalized trust, which is not specific to a counterparty (Putnam 1993, Fukuyama 1995). Generalized trust refers to the trust one has in an unknown other member of society (Nannestad 2008). Like specific trust, generalized trust 
is viewed as improving the performance of governance modes. Research focusing on within-firm activity has found that firms in high-trust regions or countries delegate more and are more decentralized (Bloom et al. 2012, Cingano and Pinotti 2016, Gur and Bjørnskov 2017, Van Hoorn 2017). Research focusing on markets, or between-firms activity, has shown that generalized trust is linked to greater economic growth and higher income levels (Knack and Keefer 1997, Algan and Cahuc 2010, 2013).

The present study investigates the role that generalized (instead of dyadic) trust plays in organizing activity by analyzing a firm's degree of external sourcing, or the extent to which it relies on external versus internal parties.

Generalized Trust. Generalized trust has been interpreted in two ways in the literature (Nannestad 2008). The first way is as trust or a willingness to be vulnerable to unknown others (e.g., Uslaner 2002). The second way is as perceived trustworthiness or a belief whether unknown others are trustworthy (e.g., Guiso et al. 2008 and Bloom et al. 2012). Regardless of which interpretation is adopted, both versions share the feature that generalized trust leads to trusting actions, which is most relevant for the present study.

Empirical research has found that measures of generalized trust are indeed associated with trusting actions. At the individual level, several studies have linked individuals' responses to a survey question about generalized trust with their play in a "trust game." ${ }^{11}$ Those who scored higher in their response to the generalized trust survey question tended to send more funds - that is, trust more (Glaeser et al. 2000, Fehr et al. 2002, Holm and Danielson 2005, Sapienza et al. 2013). At the level of a geographic area, the most comprehensive data are from Johnson and Mislin (2012), who linked a meta-analysis of 152 trust games played in 30 countries with generalized trust measured at the country level using the World Values Surveys. Similar to other surveys, that survey uses the following question: "Generally speaking, would you say that most people can be trusted or that you can't be too careful in dealing with people?" In countries with higher generalized trust, as found through the World Values Surveys, people send more funds in a trust game. Thus, generalized trust, as captured by survey responses, is predictive of trusting actions.

Three properties of generalized trust are worth noting. First, generalized trust is general. It does not identify the "other" who is being trusted; furthermore, it does not specify what the unknown other is supposed to do. In contrast, specific trust is used as follows: Party $\mathrm{A}$ trusts party $\mathrm{B}$ to perform action $\mathrm{X}$ (Mayer et al. 1995). Under generalized trust, party A trusts others without stipulating either party B or action X.
Second, generalized trust is shared. It varies by country (Nannestad 2008, Algan and Cahuc 2013). For example, in Europe, Denmark scores high on generalized trust, whereas Portugal scores low (Bjørnskov 2007). Generalized trust also varies by region within the same country (Tabellini 2010). In France, for example, some regions score much higher than others. Note that this "sharedness" property refers to the trustor-that is, people geographically near tend to be similarly trusting. In contrast, the "generalness" property refers to the trustee - that is, the trust is in unknown others who may or may not be in the same region as the trustor. Hence, generalized trust tends to be shared within a region (for the trustors), but is not restricted to that region (for the trustees).

Third, generalized trust is stable. Even when measured over multiple decades, it is remarkedly consistent over time by geography (Uslaner 2002). Using World Values Survey data from 1981 to 2004, Bjørnskov (2007) found that variations in countries' generalized trust levels accounted for $80 \%-85 \%$ by country fixed effects and for only $3 \%-8 \%$ by the period of data collection. ${ }^{2}$ This stability contrasts with the fragility that is often attributed to dyadic trust (Kramer 1999). Two explanations have been offered for the stability of generalized trust. The first is that generalized trust is a social norm that is passed on from one generation to the next (Uslaner 2008, Algan and Cahuc 2010). One view of trust is that of a decision under uncertainty with an (implicit) calculus of benefits and costs (Coleman 1990). This description seems to fit dyadic, as suggested by research on experience with the partner affecting the perceived benefits and costs of the relationship (for a meta-analysis, see Vanneste et al. 2014). Another view is that as norm-driven based on what is appropriate (Nannestad 2008). This description better fits that of generalized trust as a social norm and suggests that collective experiences may matter more than individual experiences (Uslaner 2002).

The second explanation for stability is that generalized trust has its origins in long-term historical factors. Tabellini (2010) found a link between current generalized trust levels in European regions and (1) historical political factors (strength of political institutions from 1600 to 1850) as well as (2) historical educational factors (literacy rates around 1880). Durante (2010) found, while controlling for those two factors, that current generalized trust is associated with weather conditions from 1500 to 1750 (but not those from 1900 to 2000). The argument is that these conditions affected food production and the need for collective action and risk-sharing arrangements, allowing a norm of generalized trust to emerge. This norm has persisted over time, even when variations in local weather conditions are much less important nowadays for the ability to obtain food. 
These three properties of generalized trust are central to the present study. First, because generalized trust is general, we expect it to affect not just a firm's relationship with a specific supplier, but relationships with all suppliers. Hence, we look at a firm's portfolio of relationships. Second, because generalized trust is shared, we focus on firms' differences between regions. Third, although generalized trust is stable, we anticipate that its consequences may differ over time. To help uncover the mechanism through which generalized trust affects firms' behavior and performance, we contrast generalized trust's consequences before and during the Great Financial Crisis.

External Sourcing. The choice of governance mode has often been studied in the context of vertical relationships - that is, between an upstream and a downstream unit (Williamson 1975, Grossman and Hart 1986). The upstream unit provides a service or product to the downstream unit, or, equivalently, the latter sources a service or product from the former. When both units belong to the same firm, the relationship is internal (a within-firm relation); when the units belong to different firms, the relationship is external (a between-firms relation).

Whereas initial work on the choice of governance mode focused on the product or service itself as the unit of analysis (Williamson 1975; for meta-analyses, see David and Han 2004 and Geyskens et al. 2006), the relational view extended the unit of analysis to the firm level (Dyer 1996, Gulati et al. 2000). In focusing on relationships between firms, this view argues that the collection of products and services sourced externally provides important insights regarding a firm's value creation and capture (Dyer and Singh 1998). At the firm level, researchers have shown that the extent of external sourcing varies not only across firms (Murray and Kotabe 1999), but also within firms over time (Jacobides 2005). This shift in the unit of analysis is relevant to exploring how generalized trust shapes the behavior of firms across regions. With regard to the choice of governance mode, shifting the analysis to the firm level allows us to address region-level factors (e.g., generalized trust) rather than input-level factors (e.g., asset specificity) and how the former, in turn, might shape the extent of external sourcing.

Economic Downturn. We use the context of the Great Financial Crisis to better understand the mechanisms through which generalized trust operates. A sudden and drastic economic downturn requires firms to be flexible and adjust (Williamson 1991). Indeed, failing to do so could lead to a firm's demise (Gulati et al. 2010, Bradley et al. 2011). A firm could choose to decentralize and allow decisions to be made locally (Chandler 1962, Aghion et al. 2021) or seek to reduce their reliance on external suppliers (Turnbull et al. 1992, Bidwell 2010). Thus, firms may seek to reduce their dependence on external suppliers during a downturn and thus make them absorb much of the shock of reduced demand. The role of an economic downturn is relevant to the present study because generalized trust directly affects a firm's flexibility and its ability to adjust, as we will argue.

\section{Hypotheses \\ External Sourcing}

Our baseline argument is that, compared with firms located in low generalized trust regions, firms located in high generalized trust regions have an increased willingness to enter relationships with external suppliers. Extensive research has shown that external sourcing allows for specialization and is necessary to capture gains from trade, yet it entails more vulnerability than does internal sourcing. Vulnerability is greater externally due to the lack of, or reduced effectiveness of, organizational mechanisms to control opportunism (Williamson 1975, 1985). As Williamson (1975, p. 25) notes, "Internal organization often has attractive properties in that it permits the parties to deal with uncertainty/complexity in an adaptive, sequential fashion without incurring the same type of opportunism hazards that market contracting would pose." Indeed, an organization serves to integrate the actions of individuals whose interests may differ (e.g., March and Simon 1958 and Puranam et al. 2014). There are many organizational mechanisms to enhance incentive alignment; these include hierarchy (Williamson 1975), rules (March and Simon 1958), goals (Galbraith 1973), monetary and nonmonetary rewards (Simon 1951, Kretschmer and Puranam 2008), monitoring (Holmström 1982), socialization (Edström and Galbraith 1977), and identification (March and Simon 1958). Whereas parties belonging to the same firm can benefit from these mechanisms, parties belonging to different firms will find them more difficult to apply. Some within-firm mechanisms can be replicated (albeit to a lesser extent) between firms; yet others simply cannot (e.g., on the limits of joint goals between firms, see Dussauge and Garrette 1999; on rewards, see Holmström 1999; and on identification, see Kogut and Zander 1996).

Because vulnerability is greater externally than internally, the types of products and services exchanged differs (Gibbons 2003). Those associated with higher risk of moral hazard are more likely internal than external (Williamson 1975). We argue that generalized trust reduces the perceived associated moral hazards and, thus, increases the types of products and services that are obtained through external sourcing. This 
argument mirrors that made of dyadic trust operating as a shift parameter for governance costs (Gulati and Nickerson 2008). More generally, dyadic trust has long been viewed as a mitigator of moral hazard concerns that also fosters greater mutual adjustment among the parties (e.g., Bradach and Eccles 1989). Indeed, decades of empirical research has shown that transaction costs are reduced (Connelly et al. 2018), such that firms will have a greater propensity to externalize work (Gulati 1995b). Although the focus of much prior research has been on trust that originates among dyads, generalized trust has also been shown to lead to a greater willingness to be vulnerable (Johnson and Mislin 2012). This, in turn, suggests that firms located in high generalized trust regions are more likely to enter external relationships to capture gains from trade. ${ }^{3}$ Thus:

Hypothesis 1. Generalized trust is positively associated with external sourcing.

Whereas generalized trust leads to an increased willingness to enter relationships with external suppliers, we argue that an economic downturn leads to an increased willingness to reduce or exit those relationships. In general, it is easier to scale down external rather than internal relationships in response to a demand shock (Van Mieghem 1999). This flexibility is one of the key drivers for choosing external over internal sourcing in the first place (Lafontaine and Slade 2007, Bidwell 2010). From a financial perspective, for a focal firm, costs are more variable for an external than an internal supplier. For example, from the perspective of a focal firm, the costs of equipment are fixed if it produces something internally, but not externally. External sourcing is a variable cost, whereas sourcing internally has both fixed and variable costs. As a result, reducing volume with an external supplier leads to immediate cost savings, but not with an internal supplier if some of the costs are fixed. From a social perspective, emotional bonds are stronger with an internal rather than an external supplier because of the shared identity formed by the firm boundary (Santos and Eisenhardt 2005). Indeed, firing an internal colleague differs from firing an external associate or firm.

In light of the above financial and social considerations, in the event of a negative demand shock, such as in an economic downturn, volume is reduced more with external than internal suppliers. These arguments hold for inputs simultaneously obtained from internal and external suppliers, but also for those exclusively obtained from either internal or external suppliers. As Williamson (1991) suggested, compared with internal organizing, external organizing is better suited for dealing with demand shocks when autonomous changes are required. Thus:
Hypothesis 2. An economic downturn is negatively associated with external sourcing.

Building on our arguments above, we next argue that, compared with firms located in low generalized trust regions, firms located in high generalized trust regions not only have an increased willingness to enter relationships with external suppliers, but also a decreased willingness to exit those relationships. This is based on the premise that generalized trust may lead to a greater commitment to exchange partners. Cook and Emerson (1978) described commitment as a desire to continue a relationship with an existing partner given the possibility of starting a relationship with another party, even if continuing contravenes short-term interests. Commitment, or the lack thereof, has been used as a key differentiator among interorganizational relationships (Levinthal and Fichman 1988, Ring and Van de Ven 1994).

We posit that generalized trust enhances commitment to external suppliers as follows. One of the key advantages of generalized trust is that it helps people bond (Putnam 1993, Fukuyama 1995). In a social sense, generalized trust increases participation in shared activities (Stolle 2001). For example, people are more likely to become members in voluntary associations (including local or parent associations; sports or leisure associations; or organizations involved in cultural activities, music, or education) or engage in volunteering (Van Ingen and Bekkers 2015). In an emotional sense, generalized trust expands who we care about. For example, generalized trust is associated with increased blood donations (Guiso et al. 2004). As such, generalized trust helps in addressing social dilemmas, including tax evasion (Rothstein 2000). These consequences of generalized trust derive from its moralistic basis (Uslaner 2002). Generalized trust creates a feeling of a moral obligation to help others. Hence, once bonds are formed, they are likely to persist because one cannot let the other down. Thus, generalized trust helps create and sustain bonds with others.

Because generalized trust enhances commitment to others, we suggest that it also does so with external suppliers. Whereas commitment to internal parties is typically substantial because of a firm boundary that establishes a common authority and reinforces a shared identity (Kogut and Zander 1996, Santos and Eisenhardt 2005), commitment to external parties is not a given. In fact, a difference in commitment influences the choice between internal and external sourcing (Lafontaine and Slade 2007). We argue that, compared with firms in low generalized trust regions, those in high generalized trust regions are more committed to their external suppliers and, hence, less willing to exit from these relationships. 
If the commitment level by firms in high generalized trust regions is indeed a key factor, then we should observe differences with low generalized trust regions when external relationships are at risk for being terminated. An economic downturn is such an occasion (cf. Gulati and Higgins 2003 and Bradley et al. 2011). Whereas we would expect that in an economic downturn firms would reduce external sourcing relative to internal sourcing (see Hypothesis 2), the effects are likely to vary depending on the level of generalized trust in the region. If generalized trust leads to greater commitment to external suppliers, then these relationships are more likely to continue, even in adverse conditions (Gargiulo and Ertug 2006). To the extent that firms located in high generalized trust regions are more committed to their external suppliers than firms located in low generalized trust regions, firms located in high generalized trust regions reduce their external sourcing less. In a high generalized trust region, firms are more likely to continue with their external suppliers, even in the face of adverse circumstances. In a low generalized trust region, firms are more likely to discontinue with their external suppliers as the situation demands. Thus:

Hypothesis 3. Generalized trust weakens the negative relationship between an economic downturn and external sourcing.

Firm Performance. Do firms located in high generalized trust regions benefit from external sourcing more or less compared with those in low generalized trust regions? On the one hand, generalized trust increases commitment to other parties, which weakens incentives for these parties to continue to perform (Gargiulo and Ertug 2006). If suppliers perform well, they may expect to keep or expand their business. If suppliers perform poorly, they may lose part or all of their business. Hence, the threat of termination in the event of underperformance is a key motivator in external supplier relationships (Vanneste and Frank 2014). Commitment is the opposite of a termination threat and, thus, can weaken incentives.

On the other hand, generalized trust can help parties adjust to changing circumstances. Adjustment difficulties arise especially when both parties need to make coordinated changes (Williamson 1991, Gulati et al. 2005). A concern is that one party may not want to act unless the other party adjusts first or that one party may be reluctant to adjust because circumstances may change again (Gulati et al. 1994). Generalized trust is beneficial because it encourages taking trusting actions, even without fully knowing the other's future actions. Thus, firms in high generalized trust regions are more likely to initiate necessary adjustments with their external suppliers. Furthermore, generalized trust may also promote flexibility (cf. Cuypers et al. 2021). Because generalized trust is associated with enhanced commitment, there is less concern for immediate wins. Hence, firms in high generalized trust regions may adopt a more long-term orientation, allowing them to be more flexible in the short-term.

Thus, generalized trust is a double-edged sword: It may weaken or strengthen any benefits of external sourcing. Given the opposing effects of commitment and adjustment, it is unclear whether firms in high or low generalized trust regions perform better with external sourcing. Therefore, the performance outcome should depend on which of these two issues is more salient at a given time. We can expect a given level of external sourcing to perform better with high generalized trust when the need for adjustments is high. In an economic downturn, circumstances may change rapidly and drastically, requiring adjustments. High generalized trust is thus especially beneficial in an economic downturn. Moreover, in an economic downturn, it is plausible that the negative effects of commitment are reduced because even suppliers to firms in high generalized trust regions realize that their relationships are at risk. Thus, a potential upside of generalized trust (adjustment effect) is strengthened, while a potential downside of generalized trust (commitment effect) is weakened. Hence:

Hypothesis 4. An economic downturn positively moderates the interaction between external sourcing and generalized trust on firm performance.

\section{Methods}

\section{Data Sources}

Regions. Generalized Trust. The generalized trust data are from the 2008 European Values Study (EVS), which was administered from March 2008 to March 2010 (EVS 2016; for an application, see Van Hoorn 2017). The EVS covers all European countries with a population of at least $100,000 .^{5}$ More than 66,000 respondents were asked about their basic human values, including their trust in people. The EVS format is similar to that of the World Values Survey (for applications, see Bloom et al. 2012, Cingano and Pinotti 2016, and Gur and Bjørnskov 2017). For the purposes of the present study, EVS is better suited because (1) for Europe, it has more respondents and covers more countries; and (2) it provides a more fine-grained regional classification, which we use when linking to other data sources.

Regional Controls. Other regional data are drawn from Eurostat, the statistical office of the European Union (EU). ${ }^{6}$ Eurostat provides region-specific annual data on demographics, the economy, and the labor 
market. Eurostat covers all countries of the EU-a subset of the countries covered by the EVS.

Companies. Company data are from Amadeus and are provided by Bureau van Dijk. Amadeus contains information on about 20 million companies across Europe. The data originate from national company registers. Amadeus provides annual financial information for the preceding 10 years, as well as each company's most recent address. Financial data take up to two years to appear in Amadeus. We purchased an Amadeus snapshot from 2012. This snapshot contains financial data corresponding to the EVS' sampling period (2008-2010), and it enables us to ensure that the addresses Amadeus provides correspond (as nearly as possible) to the companies' actual addresses during the EVS sampling period.

Period. The merged data cover the period from 2006 to 2010 because there is less coverage for many regional controls before 2006. Company data and regional controls are measured annually. We follow previous research in treating generalized trust as fixed. For example, Bloom et al. (2012) measured generalized trust as the average across four waves of the World Values Survey (from 1981 to 2004). Treating generalized trust as fixed is valid if generalized trust is stable over time; the evidence indicates that it is (Uslaner 2002, Bjørnskov 2007). Using the next European Values Study conducted from 2017 to 2019 (EVS 2020), we find that generalized trust for regions included in both surveys is indeed strongly correlated, even when measured about nine years apart $(r=0.83, n=$ 136 regions). ${ }^{7}$

\section{Sample}

Countries. We explore the variation of generalized trust within a country. Of the 27 member countries of the European Union in 2010, 12 are included: the Czech Republic, Denmark, France, Germany, Hungary, Italy, Poland, Portugal, Romania, Slovakia, Spain, and the United Kingdom. The 15 excluded countries are Cyprus, Estonia, Latvia, Lithuania, Luxembourg, Malta (each contains only one region), Finland (the boundaries of all but one region were adjusted during the time period studied, affecting data availability), Ireland and Slovenia (only two regions each, and no variation in generalized trust), Belgium (missing company data), Bulgaria (missing company and regional data), Austria and the Netherlands (fewer than 1,000 companies with relevant data in Amadeus), Sweden (data protection prevented extraction of the relevant data from Amadeus), and Greece (not covered by Amadeus).
Regions. Each country is divided into Nomenclature of Territorial Units for Statistics (NUTS) regions. NUTS is a hierarchical classification. For example, Cambridge is in Cambridgeshire (NUTS3: UKH12), which is in the East Anglia (NUTS2: UKH1), part of East of England (NUTS1: UKH) in the United Kingdom (NUTSO: UK). NUTS2 is the lowest level for which trust data are available. Hence, in the present study, the term "region" refers to a NUTS2 region, which comprises, on average, 1.8 million inhabitants and 16,000 square kilometers (Eurostat 2011).

Of the 196 regions of the included countries, 145 regions are included. These 145 regions account for $84 \%$ of total gross domestic product (GDP) and $88 \%$ of the total population. Regions with missing data are excluded. ${ }^{8}$ First, two regions had incomplete data for the regional controls. Second, 11 regions had no trust data. Note that the EVS does not cover most overseas regions (such as Réunion, a French island in the Indian Ocean). Third, 38 regions had insufficient trust data.

We face a tradeoff between increasing the number of required respondents per region and decreasing the number of regions included in the sample. Increasing the threshold for the number of respondents decreases the standard error of the measure of generalized trust, but increases that of its regression coefficient. The reduction in the measure's standard error is nonlinear. With few respondents, adding an additional respondent decreases the standard error substantially. With many respondents, adding an additional respondent decreases it only marginally. At around 30 respondents, the effect of adding an additional respondent drops off sharply. ${ }^{9}$ Hence, we require at least 30 respondents in a region. For the regions in our sample, the number of respondents varied between 30 and 598 with an average of 124 .

In the regressions, observations are weighted by the inverse of the standard error of generalized trust (Tabellini 2010). Regions with more respondents get greater weight than regions with fewer respondents. Furthermore, we conduct additional analyses, while requiring at least 50 respondents, which leads to excluding an additional 39 regions.

Companies. To focus on companies located in a single region, we excluded large firms and included only small- and medium-sized enterprises. SMEs are much more likely than large firms to be located in a single region. Furthermore, we excluded SMEs that reported consolidated financial statements. SMEs reporting on a single, rather than on multiple, entities are more likely located in a single region.

In the EU, SMEs constitute $99.8 \%$ of all enterprises. ${ }^{10}$ The European Commission defines SMEs as "enterprises which employ fewer than 250 persons 
and which have an annual turnover not exceeding EUR 50 million, and/or an annual balance-sheet total not exceeding EUR 43 million." ${ }^{\prime 11}$ We applied the filter "fewer than 250 persons and more than a single person." With respect to financial criteria, we applied the European Commission's "and" (not its "or") condition so that the turnover and balance-sheet criteria must both hold; this said, $99 \%$ of the companies that meet the turnover criterion also meet the balancesheet criterion (and vice versa). To ensure that the financial data were comparable, we excluded financial companies (industries 64-66 of the European Classification of Economic Activities (NACE2)).

Companies are matched to regions based on postal code (otherwise the city name) using the address in Amadeus. Eurostat provides postcode-region correspondence tables for all of our sample countries except France, Poland, and Spain. ${ }^{12}$ For these three countries, we constructed correspondence tables based on information from their respective national postal organizations. In each country, more than $95 \%$ of the companies were matched to a region, except in Denmark, Italy, Portugal, Romania, and Slovakia. For these countries, we additionally used Eurostat correspondence tables that linked local administrative units to regions. ${ }^{13}$ In many cases, the city name given in the company address corresponded to a local administrative unit. Using these additional tables resulted in a company-region match for more than $95 \%$ of companies in all countries (except Denmark, for which the corresponding figure was 93\%). Overall, 98\% (on average) of the companies were matched in each country, and more than $99 \%$ were matched across all countries. Because regressions are estimated using only companies with multiple observations, the final sample size for the regions we study is 1,063,915 companies. Table 1 reports the number of companies on a per-country basis.

\section{Variables}

Regions. Generalized Trust. This variable is measured as the regional average response to the following question: "Generally speaking, would you say that most people can be trusted or that you can't be too careful in dealing with people?" The answer categories are "most people can be trusted" (1) or "can't be too careful" (0). This question was asked in the national language of the country in which the survey was administered. The resulting measure has often been used (e.g., Knack and Keefer 1997 and Guiso et al. 2008). Generalized trust is based on long-term factors (e.g., strength of political institutions from 1600 to 1850 and literacy rates around 1880 (Tabellini 2010) and weather conditions from 1500 to 1750 (Durante 2010)), which predate current sourcing arrangements (and, in fact, $99.99 \%$ of our sample firms) by many
Table 1. Sample Overview

\begin{tabular}{lrrrrr}
\hline & & & \multicolumn{3}{c}{ Generalized trust } \\
\cline { 3 - 6 } Countries & Companies & Regions & Min & Mean & Max \\
\hline Czech Republic & 52,363 & 8 & 0.11 & 0.30 & 0.47 \\
Denmark & 3,159 & 5 & 0.71 & 0.76 & 0.80 \\
France & 98,728 & 18 & 0.18 & 0.26 & 0.39 \\
Germany & 5,229 & 20 & 0.16 & 0.39 & 0.72 \\
Hungary & 77,670 & 7 & 0.13 & 0.19 & 0.33 \\
Italy & 209,868 & 15 & 0.17 & 0.31 & 0.55 \\
Poland & 39,068 & 16 & 0.10 & 0.27 & 0.45 \\
Portugal & 134,015 & 5 & 0.00 & 0.16 & 0.26 \\
Romania & 118,061 & 8 & 0.07 & 0.17 & 0.32 \\
Slovakia & 12,702 & 4 & 0.11 & 0.14 & 0.18 \\
Spain & 302,774 & 14 & 0.08 & 0.32 & 0.59 \\
United Kingdom & 10,308 & 25 & 0.23 & 0.41 & 0.61 \\
Total & $1,063,915$ & 145 & & & \\
\hline
\end{tabular}

Note. For generalized trust, min is the regional minimum, max is the regional maximum, and mean is the mean across regions.

decades, if not several centuries. These long-term factors suggest that generalized trust is exogenous from a firm's perspective (Bloom et al. 2012) and that it is unlikely to be driven by current sourcing arrangements.

The SME may or may not be in the same region as a supplier. Does higher generalized trust imply higher trust in others from a different region? To address this question, we analyze data from the European Election Studies' (EES') Voter Study 2004 (Schmitt et al. 2009). In each participating European country, about 1,000 respondents were asked: "Now I would like to ask you a question about how much trust you have in people from various countries. Can you please tell me for each, whether you have a lot of trust of them or not very much trust?" For example, German respondents were asked about their trust in people in Germany, in people in the Czech Republic, in people in Denmark, and so on. For each country, we average the responses about trust in people in the same country and the responses about trust in people in other countries. Trust in same country and trust in other countries are positively correlated $(r=0.60, n=19$ countries).

We matched these data with the data we used to measure generalized trust. Generalized trust (from the EVS and for this purpose calculated at the country level) and trust in other countries (from the EES) are again positively correlated ( $r=0.38, n=19$ countries). Hence, the evidence suggests that higher generalized trust is positively associated higher trust in others in a different geographic area.

Regional Controls. We select regional controls using the procedure described in Selection of Control Variables. As candidate regional controls, we consider variables from Eurostat that were available for most 
regions; these variables include GDP, size of population, and size of geographic area. Table A1 in the online appendix provides an overview of the 22 candidate regional controls (or 66 controls when their higher-order terms are included, as explained in the appendix).

Companies. External Sourcing. This variable is measured as bought-in materials and services expenses divided by operating expenses. Materials and services expenses are often unreported, but can be calculated by subtracting labor expenses from operating expenses (Brynjolfsson and Hitt 2003). ${ }^{14}$ Operating expenses are calculated as operating revenue minus earnings before interest, taxes, depreciation, and amortization (Brynjolfsson and Hitt 2003).

The conceptual origin of this measure is the valueadded model (Accounting Standards Steering Committee 1975; for a recent application, see Lieberman et al. 2017). Value added is the difference between revenue and bought-in materials and services from suppliers. This difference can then be attributed to various categories: paying employees (wages), paying capital providers (interest and dividends), paying the government (taxes), and maintaining and expanding assets (depreciation and retained profits). We focus on one element from this model: bought-in materials and services from suppliers (as normalized by operating expenses).

Performance. We measure performance in two ways: return on assets (ROA) and return on sales (ROS) (Vanneste 2017). We use earnings before interest and taxes for returns, total assets for assets, and operating revenue for sales. We winsorize the variables (at the upper and lower $5 \%$ of the distribution) to reduce the effect of extreme values. ${ }^{15}$

Company Controls. We select company controls using the same procedure as for the regional controls (see Selection of Control Variables). As candidate company controls, we consider variables from Amadeus that were available for most countries and companies; these variables include age, legal form, and total assets. Table A2 in the online appendix provides an overview of the eight candidate company controls (or 298 controls when their higher-order terms and interactions are included, as explained in the appendix).

Other. Economic Downturn. We consider the economic downturn resulting from the Great Financial Crisis. The crisis appeared first in the financial sector and went on to affect all other sectors. In 2007Q3, BNP Paribas suspended redemptions from three of its mutual funds, one of the earliest clear signs of the crisis in Europe. ${ }^{16}$ In 2008Q2, the EU GDP dropped for the first time since the start of the crisis. In 2010, GDP growth in some EU countries was still negative, and EU overall unemployment had not yet peaked. ${ }^{17}$ Hence, we code the years 2008-2010 as "economic downturn" and the year 2007 as "transition to downturn." The year 2006 is the baseline-that is, prior to the economic downturn. We also estimated regression with separate indicators for each year of 2008-2010. The results are similar to those reported here, which are easier for exposition.

\section{Selection of Control Variables}

We have access to many potential control variables. This situation may arise if data are "big" (e.g., the data set has many variables) or if a flexible specification is chosen (e.g., a small number of variables is used to create many transformations and interactions). A challenge is to select control variables. If we include many controls for a flexible specification, then it is unclear how many becomes too much. If we select few control variables and ignore alternative explanations, then we may incur omitted variable bias. Belloni et al. (2014a) showed that a single-selection procedure that retains only the significant variables can lead to omitted variable bias. Instead, they proposed a double-selection procedure that does not suffer from this problem. This procedure enables a systematic selection from a large set of control variables and is flexible with respect to functional forms and interactions. Therefore, we used the Belloni et al. $(2014 a, b)$ doubleselection procedure. Furthermore, this algorithmic procedure-compared with an ad hoc selection of control variables-may reduce researcher bias and enhance replicability. The appendix describes the application of this procedure to the data.

The double-selection procedure is data-driven, but it is the researcher who provides the set of potential control variables as input. We need to keep two issues in mind when constructing this set. First, on uncorrelated variables, the overarching goal is to account for factors that correlate with both the dependent and key independent variables. We can ignore variables that are unlikely to satisfy these criteria. This said, the double-selection procedure specifically checks for these correlations, while guarding against overfitting. Second, on correlated variables, the procedure cannot distinguish between good and so-called bad controls (Angrist and Pischke 2008); hence, we as researchers must. Consider an example in which the independent variable is generalized trust and the dependent variable is external sourcing in year 2008. Although external sourcing in year 2009 is likely correlated with both variables, we do not want to include it in the potential control set because it is itself an outcome of generalized trust. A similar issue arises with a mediator 
variable. We cannot hand over the responsibility to the double-selection procedure, but must ourselves decide on inclusion based on the effect we are interested in estimating. Thus, in addition to data completeness, we used the following criteria for choosing potential control variables: (1) Include those that may correlate, even if remotely, with an outcome variable; and (2) not include those that are themselves outcome variables (e.g., external sourcing in a subsequent year).

\section{Results}

\section{Data Description}

Table 1 shows, for each country, generalized trust averaged across regions, as well as the regional minimum and maximum. Substantial variation exists between countries: The lowest average is 0.14 (Slovakia), and the highest is 0.76 (Denmark). Considerable within-country variation is also evident. In Germany, for example, generalized trust ranges from 0.16 in the lowest-scoring region to 0.72 in the highest. Generalized trust scores for the lowest German region are roughly equal to those for the average Slovakian region, and the highest are roughly equal to the average Danish region. The map presented as Figure 1 shows the level of generalized trust for each region included in the sample. In the regression specification, we will exploit the differences in generalized trust within a given country.

Table 2 presents the summary statistics for the key variables, and Table 3 reports the pairwise
Table 2. Descriptive Statistics of Key Variables

\begin{tabular}{lcrccc}
\hline Variable & $N$ & Min. & Mean & Max. & SD \\
\hline Generalized trust & 145 & 0.00 & 0.32 & 0.80 & 0.16 \\
External sourcing & $4,262,785$ & 0.00 & 0.70 & 1.00 & 0.20 \\
ROA & $4,262,785$ & -0.36 & 0.04 & 0.34 & 0.15 \\
ROS & $4,262,785$ & -0.34 & 0.02 & 0.22 & 0.12 \\
\hline
\end{tabular}

correlations. External sourcing has a mean of 0.70 and a standard deviation of 0.20 . The vast majority of firms source externally at more than $50 \%$, underscoring the importance of relationships between firms.

\section{Hypotheses}

To test Hypothesis 1, model (1) of Table 4 shows the regression with external sourcing as the dependent variable and generalized trust as the key independent variable. This regression includes country, industry, and year fixed effects, as well as the control variables chosen through the double-selection procedure. There are 4,262,785 observations based on data for 1,063,915 firms located in 145 regions. Observations are weighted by the inverse standard error of generalized trust. We cluster robust standard errors by region to allow for nonindependence of observations within the same region (a procedure that also accounts for the nonindependence of observations from the same firm). Clustering by region yields just 144 residual degrees of freedom, whereas clustering by firm would result in 1,063,914 residual degrees of freedom and much smaller standard errors. Thus, the reported standard

Figure 1. (Color online) Generalized Trust Within Countries

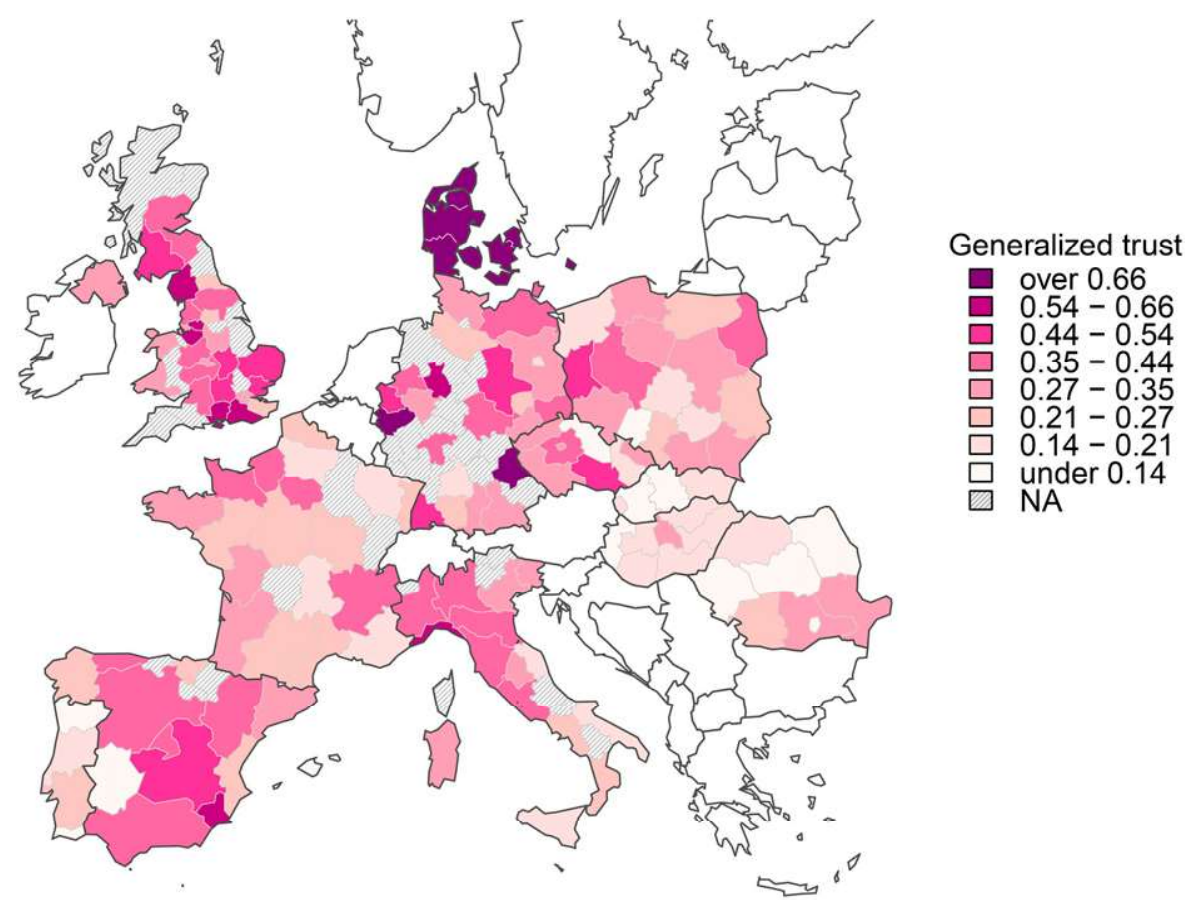


Table 3. Pairwise Correlations

\begin{tabular}{|c|c|c|c|c|c|c|c|c|c|c|c|c|}
\hline Variable & (1) & (2) & (3) & (4) & (5) & (6) & (7) & (8) & (9) & (10) & $(11)$ & (12) \\
\hline \multicolumn{13}{|l|}{ (1) Generalized trust } \\
\hline (2) External sourcing & -0.07 & & & & & & & & & & & \\
\hline (3) $R O A$ & -0.00 & 0.05 & & & & & & & & & & \\
\hline (4) $\mathrm{ROS}$ & 0.01 & 0.04 & 0.85 & & & & & & & & & \\
\hline (5) Economic downturn & 0.00 & -0.06 & -0.11 & -0.10 & & & & & & & & \\
\hline (6) Transition to economic downturn & 0.00 & 0.04 & 0.07 & 0.07 & -0.65 & & & & & & & \\
\hline (7) $5 \times 1$ & 0.46 & -0.08 & -0.09 & -0.08 & 0.82 & -0.53 & & & & & & \\
\hline (8) $6 \times 1$ & 0.19 & 0.02 & 0.07 & 0.06 & -0.59 & 0.91 & -0.48 & & & & & \\
\hline (9) $2 \times 1$ & 0.78 & 0.52 & 0.03 & 0.03 & -0.04 & 0.02 & 0.32 & 0.17 & & & & \\
\hline (10) $2 \times 1 \times 5$ & 0.40 & 0.23 & -0.07 & -0.06 & 0.76 & -0.49 & 0.91 & -0.45 & 0.49 & & & \\
\hline (11) $2 \times 1 \times 6$ & 0.17 & 0.14 & 0.07 & 0.06 & -0.57 & 0.87 & -0.46 & 0.96 & 0.24 & -0.43 & & \\
\hline (12) $2 \times 5$ & -0.03 & 0.31 & -0.08 & -0.08 & -0.89 & -0.58 & 0.71 & -0.53 & 0.15 & 0.83 & -0.51 & \\
\hline (13) $2 \times 6$ & -0.01 & 0.16 & 0.07 & 0.06 & -0.62 & 0.95 & -0.51 & 0.86 & 0.09 & -0.47 & 0.91 & -0.55 \\
\hline
\end{tabular}

Note. $x \times y$ is the interaction between measure $(x)$ and measure $(y)$.

errors and $p$-values are approximately as large as those found in a typical study with 100 to 200 observations-and are not incredibly small, as one could expect in a study with millions of observations.

In line with Hypothesis 1, generalized trust is positively associated with external sourcing. This result means that SMEs' degree of external sourcing is greater for enterprises in high-trust than in low-trust regions. The coefficient is 0.031 ( $p<0.01)$; thus, Hypothesis 1 is supported. Going from a region whose trust level is one standard deviation below the mean to a region whose trust level is one standard deviation

Table 4. Regressions for External Sourcing

\begin{tabular}{|c|c|c|c|}
\hline & $\begin{array}{l}\text { External } \\
\text { sourcing } \\
\quad(1)\end{array}$ & $\begin{array}{l}\text { External } \\
\text { sourcing } \\
\text { (2) }\end{array}$ & $\begin{array}{c}\text { External } \\
\text { sourcing } \\
\text { (3) }\end{array}$ \\
\hline Generalized trust & $\begin{array}{c}0.031 \\
(0.012)\end{array}$ & & \\
\hline Economic downturn & $\begin{array}{l}-0.017 \\
(0.002)\end{array}$ & $\begin{array}{c}-0.011 \\
(0.003)\end{array}$ & $\begin{array}{c}-0.011 \\
(0.005)\end{array}$ \\
\hline $\begin{array}{l}\text { Economic downturn } \\
\quad \times \text { Generalized trust }\end{array}$ & & & $\begin{array}{c}-0.001 \\
(0.012)\end{array}$ \\
\hline Transition to downturn & $\begin{array}{c}-0.008 \\
(0.002)\end{array}$ & $\begin{array}{c}-0.004 \\
(0.002)\end{array}$ & $\begin{array}{c}-0.006 \\
(0.004)\end{array}$ \\
\hline $\begin{array}{l}\text { Transition to downturn } \\
\quad \times \text { Generalized trust }\end{array}$ & & & $\begin{array}{c}0.008 \\
(0.011)\end{array}$ \\
\hline Controls included & Yes & Yes & Yes \\
\hline Country FE & 12 & No & No \\
\hline Industry FE & 682 & No & No \\
\hline Firm FE & No & Yes & Yes \\
\hline$n$ observations & $4,262,785$ & $4,262,785$ & $4,262,785$ \\
\hline$n$ firms & $1,063,915$ & $1,063,915$ & $1,063,915$ \\
\hline$n$ regions & 145 & 145 & 145 \\
\hline$p$ & 86 & 86 & 86 \\
\hline$R^{2}$ & 0.49 & 0.91 & 0.91 \\
\hline
\end{tabular}

Notes. $p$ is the number of control variables. Generalized trust, country, and industry are all constant by firm, so they are accounted for via firm fixed effects (FE). Robust standard errors (in parentheses) are clustered by region. Observations are weighted by the inverse of the standard error of generalized trust. above the mean corresponds to external sourcing that is greater by about 1.0 percentage point. This effect size is only modest relative to the between-firms standard deviation of external sourcing (19 percentage points).

To test Hypothesis 2, model (2) adds firm fixed effects (country and industry do not vary by firm, so they are accounted for with the firm fixed effects). No main effect is included for generalized trust because it does not vary by firm (and, therefore, is accounted for via firm fixed effects). In line with Hypothesis 1, economic downturn is negatively associated with external sourcing, so that firms externally source less during rather than before the economic downturn. The coefficient is -0.011 ( $p<0.001)$; thus, Hypothesis 2 is supported. Thus, on average, a firm's external sourcing is about 1.1 percentage points lower during rather than before the economic downturn (by comparison, the within-firm standard deviation is 7 percentage points).

To test Hypothesis 3, model (3) adds the interaction between economic downturn and generalized trust. The interaction is close to zero $(b=-0.001, p=0.93)$; thus, Hypothesis 3 is not supported. Thus, firms externally source less during an economic downturn, but not more so in low than high generalized trust regions. After presenting the main results, we will report additional analyses to explore this finding.

Table 5 reports the regressions with performance (ROA and ROS) as the dependent variables. As a baseline, models (1) and (4) report the main effect of external sourcing on performance, which is positive $(b=$ 0.083 for ROA and $b=0.044$ for ROS). This effect is substantially reduced without firm fixed effects (but with country and industry fixed effects). We obtain $b$ $=0.007$ for ROA and also for ROS (see models (1) and (4) of Table D1 in the online appendix). Thus, in our sample, high external sourcing firms do not outperform low external sourcing firms (per the estimation 
Table 5. Regressions for Performance

\begin{tabular}{|c|c|c|c|c|c|c|}
\hline & $\begin{array}{c}\text { ROA } \\
(1)\end{array}$ & $\begin{array}{c}\mathrm{ROA} \\
(2)\end{array}$ & $\begin{array}{c}\mathrm{ROA} \\
(3)\end{array}$ & $\begin{array}{c}\text { ROS } \\
(4)\end{array}$ & $\begin{array}{c}\text { ROS } \\
(5)\end{array}$ & $\begin{array}{c}\text { ROS } \\
(6)\end{array}$ \\
\hline External sourcing & $\begin{array}{c}0.083 \\
(0.005)\end{array}$ & $\begin{array}{c}0.068 \\
(0.013)\end{array}$ & $\begin{array}{c}0.073 \\
(0.018)\end{array}$ & $\begin{array}{c}0.044 \\
(0.002)\end{array}$ & $\begin{array}{c}0.049 \\
(0.007)\end{array}$ & $\begin{array}{c}0.052 \\
(0.009)\end{array}$ \\
\hline External sourcing $\times$ Generalized trust & & $\begin{array}{c}0.062 \\
(0.046)\end{array}$ & $\begin{array}{c}0.006 \\
(0.061)\end{array}$ & & $\begin{array}{c}-0.022 \\
(0.023)\end{array}$ & $\begin{array}{r}-0.067 \\
(0.031)\end{array}$ \\
\hline External sourcing $\times$ Economic downturn & & & $\begin{array}{c}-0.008 \\
(0.015)\end{array}$ & & & $\begin{array}{r}-0.004 \\
(0.007)\end{array}$ \\
\hline Generalized trust $\times$ Economic downturn & & & $\begin{array}{r}-0.053 \\
(0.034)\end{array}$ & & & $\begin{array}{r}-0.047 \\
(0.017)\end{array}$ \\
\hline External sourcing $\times$ Generalized trust $\times$ Economic downturn & & & $\begin{array}{c}0.077 \\
(0.046)\end{array}$ & & & $\begin{array}{c}0.063 \\
(0.022)\end{array}$ \\
\hline Economic downturn & $\begin{array}{c}-0.005 \\
(0.002)\end{array}$ & $\begin{array}{r}-0.005 \\
(0.002)\end{array}$ & $\begin{array}{c}0.000 \\
(0.011)\end{array}$ & $\begin{array}{r}-0.004 \\
(0.001)\end{array}$ & $\begin{array}{c}-0.004 \\
(0.001)\end{array}$ & $\begin{array}{r}-0.000 \\
(0.006)\end{array}$ \\
\hline External sourcing $\times$ Transition to downturn & & & $\begin{array}{c}0.002 \\
(0.004)\end{array}$ & & & $\begin{array}{c}0.000 \\
(0.002)\end{array}$ \\
\hline Generalized trust $\times$ Transition to downturn & & & $\begin{array}{c}0.004 \\
(0.011)\end{array}$ & & & $\begin{array}{r}-0.001 \\
(0.007)\end{array}$ \\
\hline External sourcing $\times$ Generalized trust $\times$ Transition to downturn & & & $\begin{array}{c}0.010 \\
(0.012)\end{array}$ & & & $\begin{array}{c}0.004 \\
(0.008)\end{array}$ \\
\hline Transition to downturn & $\begin{array}{c}0.000 \\
(0.001)\end{array}$ & $\begin{array}{c}0.000 \\
(0.001)\end{array}$ & $\begin{array}{c}-0.003 \\
(0.004)\end{array}$ & $\begin{array}{r}-0.000 \\
(0.001)\end{array}$ & $\begin{array}{r}-0.000 \\
(0.001)\end{array}$ & $\begin{array}{r}-0.001 \\
(0.006)\end{array}$ \\
\hline Controls included & Yes & Yes & Yes & Yes & Yes & Yes \\
\hline Country FE & No & No & No & No & No & No \\
\hline Industry FE & No & No & No & No & No & No \\
\hline Firm FE & $1,063,915$ & $1,063,915$ & $1,063,915$ & $1,063,915$ & $1,063,915$ & $1,063,915$ \\
\hline$n$ observations & $4,262,785$ & $4,262,785$ & $4,262,785$ & $4,262,785$ & $4,262,785$ & $4,262,785$ \\
\hline$n$ regions & 145 & 145 & 145 & 145 & 145 & 145 \\
\hline$p$ & 166 & 166 & 166 & 166 & 166 & 166 \\
\hline$R^{2}$ & 0.73 & 0.73 & 0.73 & 0.80 & 0.80 & 0.80 \\
\hline
\end{tabular}

Notes. $p$ is the number of control variables. Generalized trust, country, and industry are all constant by firm, so they are accounted for via firm fixed effects (FE). Robust standard errors (in parentheses) are clustered by region. Observations are weighted by the inverse of the standard error of generalized trust.

without firm fixed effects). However, a firm's increase of 1 percentage point in external sourcing is associated with higher performance of 0.083 (ROA) or 0.044 (ROS) percentage points (per the firm fixed effects estimation). One interpretation, then, is that a typical firm in the sample performs better with more external sourcing, which holds similarly regardless of whether the typical firm is low or high external sourcing at the outset. The inclusion or exclusion of firm fixed effects leads to similar interaction effects, especially the three-way interaction, which we use to test Hypothesis 4 (compare the other models of Table 5 and Table D1 in the online appendix).

Models (2) and (5) add the two-way interaction between external sourcing and generalized trust. The interaction is positive for ROA $(b=0.062)$ and negative for $\operatorname{ROS}(b=-0.022)$, and neither are significant $(p=0.17$ and $p=0.34$, respectively). These results indicate that firms located in high generalized trust regions, compared with those in low generalized trust regions, obtain similar performance benefits from external sourcing. These findings are consistent with a negative commitment effect and a positive adjustment effect.

To test Hypothesis 4, models (3) and (6) include a three-way interaction between external sourcing, generalized trust, and economic downturn as the key independent variable (and all two-way interactions). In accord with Hypothesis 4, the interaction between external sourcing, generalized trust, and economic downturn is positive $(b=0.077$ for ROA and $b=0.063$ for ROS). The significance level with ROA is $p=0.10$ and with ROS is $p<0.01$. Hence, Hypothesis 4 is supported for ROS, and not for ROA. These results indicate that firms located in high generalized trust regions, compared with those in low generalized trust regions, tend to obtain higher performance benefits from external sourcing during the economic downturn.

We illustrate the three-way interaction by investigating how it changes the two-way interaction between external sourcing and generalized trust before and during the economic downturn. To plot these changes, we use a subsample analysis in which we estimate the two-way interaction for each period (see Table D2 in the online appendix). This analysis cannot include firm fixed effects and, thus, can estimate a main effect for generalized trust, which is necessary for plotting. Per Hypothesis 4, the two-way interaction between external sourcing and generalized trust is greater during, rather than before, the economic downturn. Specifically, for ROA, it is $b=0.067$ versus 
$b=-0.016$ (this difference is statistically significant, $p=0.03$, and similar to the difference estimated in the main specification, $b=0.077$ ). For ROS, it is $b=0.007$ versus $b=-0.040$ (this difference is statistically significant, $p<0.05$, and similar to the difference estimated in the main specification, $b=0.063$ ).

Figure 2 plots these interaction effects. During the economic downturn (i.e., the right "column"), external sourcing is more strongly related to performance in high, rather than low, generalized trust regions (i.e., the full line is steeper than the dotted line for both ROA and ROS). For example, in the top right panel, high external sourcing firms outperform low external sourcing firms by 0.9 ROA percentage points in high generalized trust regions (solid line), but barely in low generalized trust regions (dashed line). An extra 0.9 ROA percentage points corresponds to an extra annual return of EUR 6,700 for a firm with average total assets. By comparison, in the sample, the median annual return is EUR 13,000, and the mean annual return is negative. Before the economic downturn (i.e., the left column), external sourcing is less strongly related to performance in high, rather than low, generalized trust regions (i.e., the full line is less steep than the dotted line for both ROA and ROS). For example, in the bottom left panel, high external sourcing firms underperform low external sourcing firms by 0.1 ROS percentage points in high generalized trust regions, but outperform by 0.4 ROS percentage points in low generalized trust regions. A difference of 0.5 ROS percentage points amounts to a reduction in annual return of EUR 4,700 for a firm with average sales. Hence, external sourcing benefits more from generalized trust during, rather than before, the economic downturn.

We make two observations. First, the two-way interaction between external sourcing and generalized trust on performance is negative, close to zero, or positive, depending on the economic conditions and the performance metric. These different findings are consistent with two countervailing mechanisms of generalized trust: a negative commitment effect and a positive adjustment effect. Second, the three-way interaction with economic downturn is positive, for both ROA and ROS. This finding is consistent with the greater need to adjust during an economic downturn.

It is important to consider the possible endogeneity of generalized trust, for which we are unable to directly control in the present study. A potential concern is that unobserved regional differences may correlate with generalized trust and the outcome variable. Incorporating the exogenous shock of the economic downturn reduces the endogeneity concern in the present study for two reasons, but does not eliminate it. First, from a theoretical standpoint, the economic downturn hypotheses raise the bar for known and unknown alternative explanations (Stinchcombe 1968). Thus, alternative explanations need to account for not only the existence of a correlation between generalized trust and the outcome variables, but also its change during an economic downturn. Second, empirically, the use of an exogenous shock combined with an interaction term yields benefits for the interpretation of potentially endogenous independent variables. Specifically, an interaction between an endogenous and exogenous variable is itself exogenous (Withers et al. 2014, Nizalova and Murtazashvili 2016, Bun and Harrison 2019). If we consider an economic downturn as exogenous, then an interaction term with generalized trust and economic downturn is consistently estimated, even when a main term for generalized trust is not. In that case, the endogeneity concern would not hold for (Hypothesis 3 and) Hypothesis 4 (but could for Hypothesis 1).

\section{Additional Analysis and Robustness Checks}

The findings broadly support the hypotheses, except Hypothesis 3 , which examined the interaction effect of economic downturn and generalized trust and economic downturn on external sourcing. To understand these findings, we estimated a model without firm fixed effects (but with country and industry fixed effects). Without firm fixed effects, the interaction effect of economic downturn and generalized trust on external sourcing is positive $(b=0.027, p=0.03$; the regression table is provided in the online appendix), which contrasts with the firm fixed effects specification $(b=$ $-0.001, p=0.93)$. When not controlling for fixed unobservable firm characteristics, external sourcing goes down more in high, than in low, generalized trust regions. When controlling for these characteristics, external sourcing goes down equally. ${ }^{18}$ One interpretation is that high and low generalized trust regions produce or attract different firms and that those firms that are more common in low generalized trust regions tend to reduce external sourcing more in an economic downturn.

Whereas the downturn period covers multiple years (2008-2010), the base period consists of only a single year (2006). We attribute changes between these periods to the economic downturn. However, if 2006 is an outlier, then these changes might be due to the specifics of 2006 instead of the economic downturn. We investigate this potential concern by comparing 2006 with 2007 ("Transition to downturn"). If 2006 is an outlier, then 2007 should behave differently. However, if they are similar, then 2006 is not an outlier.

For performance, the direct effect of transition to downturn is zero, or the same as the base period, which is the omitted category $(p=0.64$ for ROA and 
Figure 2. (Color online) The Effect of External Sourcing $\times$ Generalized Trust on Performance Is Positively Moderated by Economic Downturn
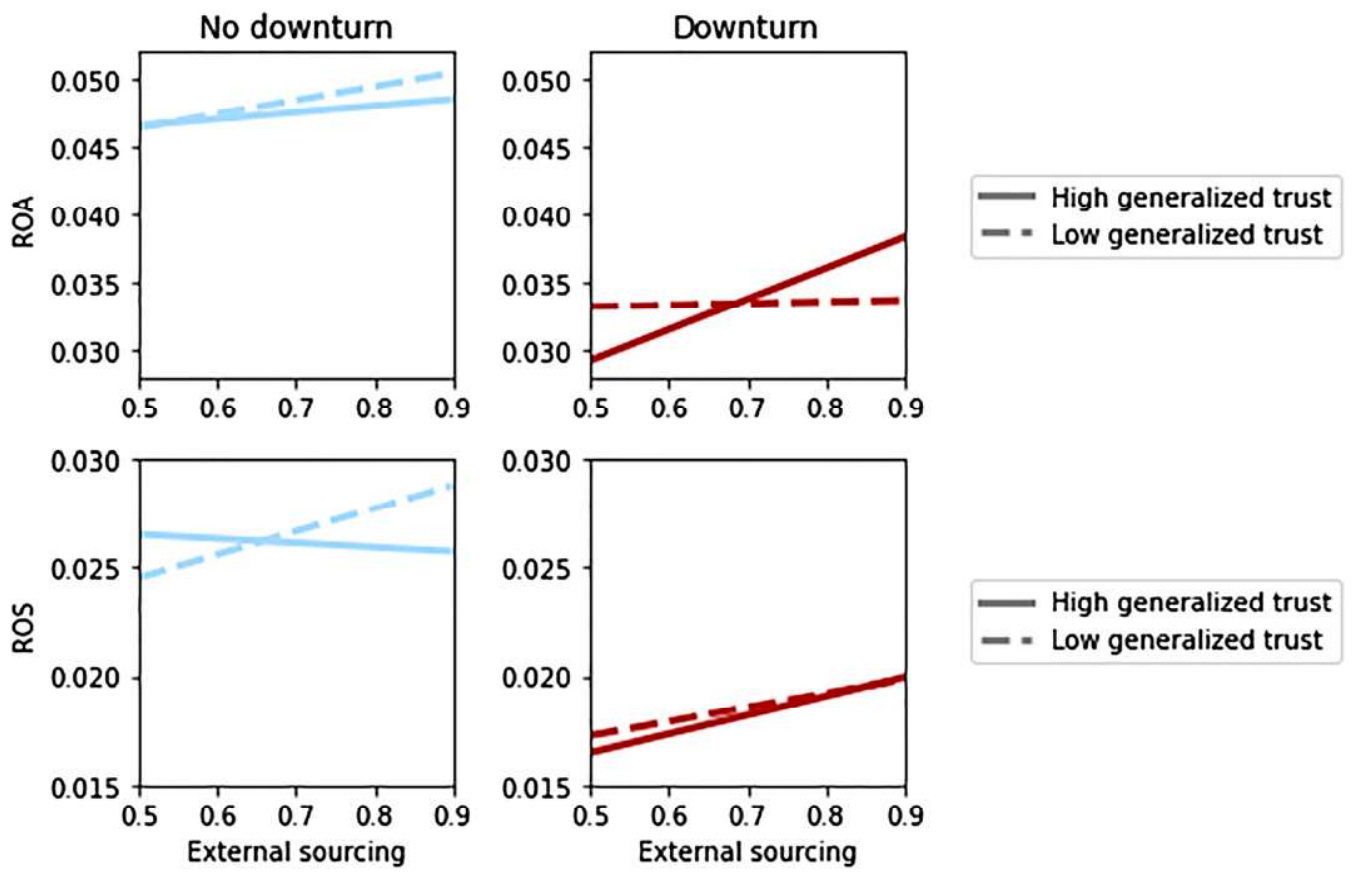

Notes. The range for external sourcing is mean \pm s.d. High generalized trust is mean + s.d. Low generalized trust is mean - s.d.

$p=0.71$ for ROS; see models (1) and (4) in Table 5). For external sourcing, the direct effect of transition to downturn is closer to zero $(p=0.02$; see model (2) in Table 4) than to the direct effect of economic downturn. Thus, 2007 behaves similarly for performance and differently, but in the anticipated direction, for external sourcing. These findings suggest that 2006 is unlikely to be an outlier and that the economic downturn played a role.

We conduct additional analyses to probe the robustness of the results. All regression tables are provided in the online appendix. Figure 3 shows the effect sizes obtained from these additional regressions. To facilitate comparisons among the various estimations, all effect sizes are in percentage points. The figure's top "row" (Hypothesis 1) shows the external sourcing difference for firms in regions of high compared with low generalized trust (voter turnout and trust in people from other countries). The row for Hypothesis 2 shows the external sourcing difference during and before the economic downturn. The row for Hypothesis 3 provides the additional external sourcing difference in an economic downturn for firms in regions of high, compared with low, generalized trust (voter turnout and trust in people from other countries). The bottom row (Hypothesis 4 for ROA and ROS, respectively) plots the additional performance benefit in an economic downturn for high, relative to low, external sourcing firms in regions characterized by high versus low generalized trust (voter turnout and trust in people from other countries). The labels "low" and "high" refer to the mean \pm standard deviation. For comparison, we include the main results (reported as "Generalized trust").

For details of the additional robustness checks, see part $C$ of the online appendix. In short, for the generalized trust survey, we used a minimum of 30 respondents per region. "Generalized trust (50 respondents)" uses instead a minimum of 50 , reducing the number of included regions to 106 from 145. The main specification focuses on SMEs, as these firms are likely located in a single region. "Generalized trust (small companies)" further reduces the possibility that a focal firm is located in multiple regions by excluding medium-sized companies (about $1 \%$ of the sample) and retaining only small-sized companies, which are most likely located in a single region. "Voter turnout" uses voter turnout for the EU parliamentary election as a proxy for generalized trust, in line with Guiso et al. (2004). Because generalized trust is not restricted to others from the same region, "Trust in other countries" reports on the EES measure for trust in people from other countries.

Overall, across different samples (50 respondents and small companies) and different measures (voter turnout and trust in people from other countries) and 
Figure 3. Effect Sizes Across Estimations
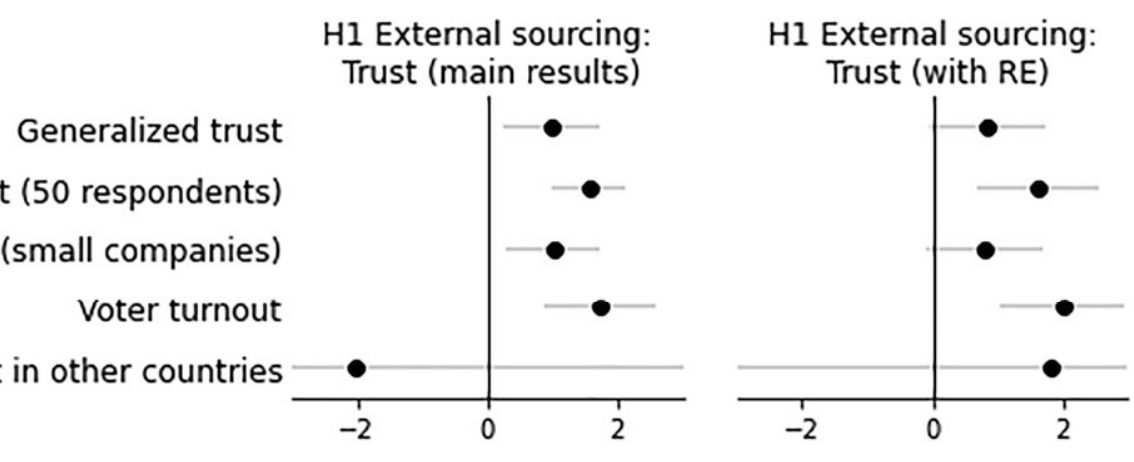

Generalized trust (50 respondents)

Generalized trust (small companies)

Trust in other countries

H2 External sourcing: Downturn

Generalized trust

Generalized trust (50 respondents)

Generalized trust (small companies)

Voter turnout

Trust in other countries
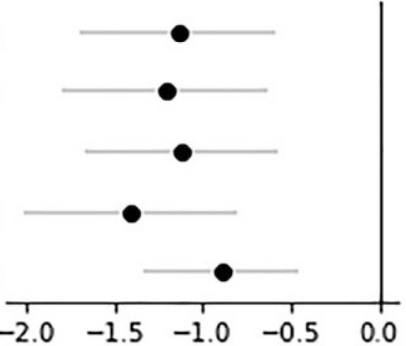

H3 External sourcing:

H3 External sourcing:

Downturn * Trust (main results) Downturn * Trust (no FE)

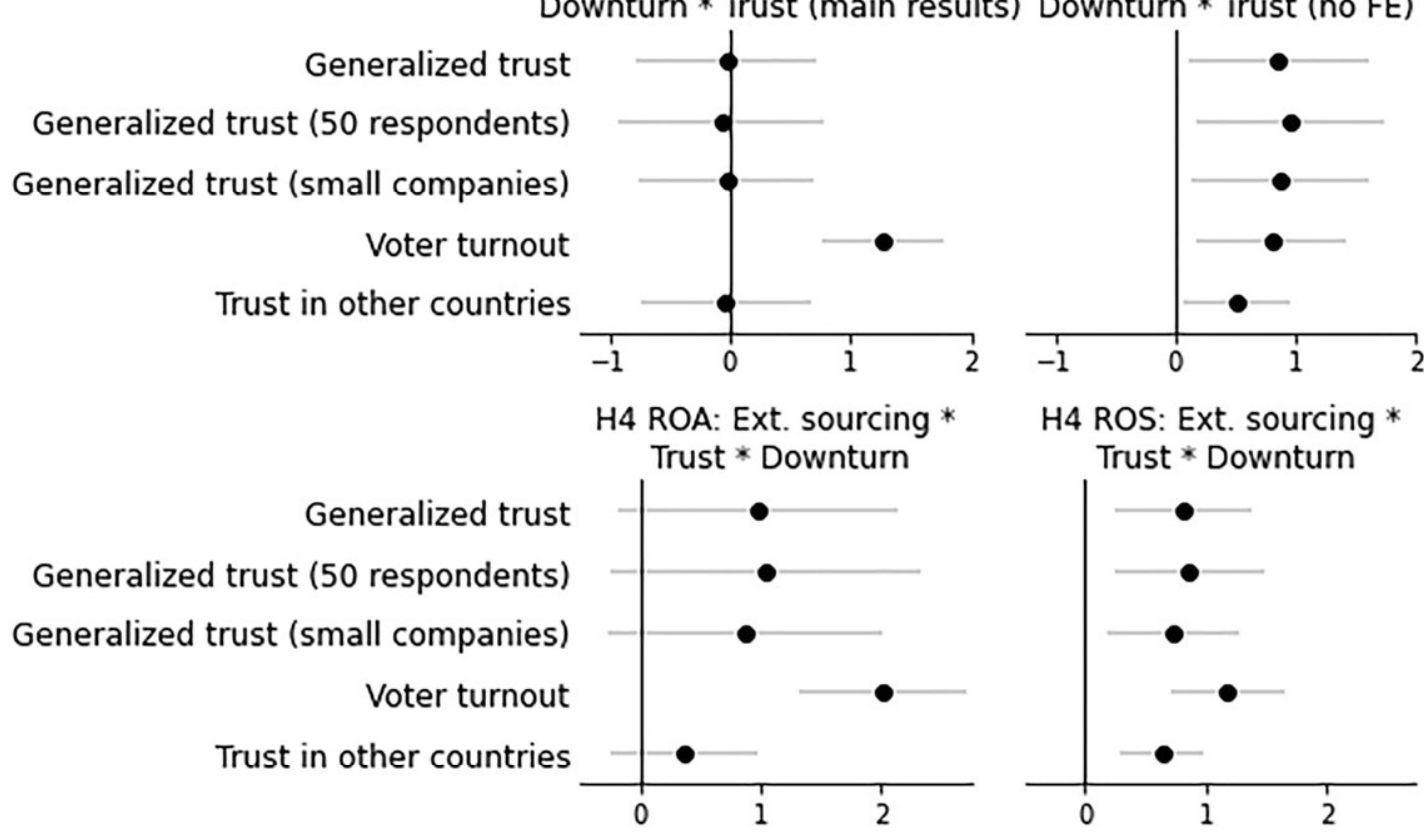

Notes. Point estimates and 95\%-CI provided for effect size (in percentage points). The number of regions is 145 (in 12 countries) for Generalized trust and Generalized trust (small companies), 106 regions (in 12 countries) for Generalized trust (50 respondents), 83 regions (in eight countries) for Voter turnout, and 112 regions (in 10 countries) for Trust in other countries.

specifications (random effects), the results are broadly similar to the main results.

\section{Discussion}

The present study was designed to explore the role of generalized trust in shaping the external sourcing and performance of firms. We find that firms in high generalized trust regions, compared with those in low generalized trust regions, source more externally (but do not reduce external sourcing less in an economic downturn) and tend to benefit more from external sourcing during an economic downturn. It demonstrates that generalized trust does indeed shape organizational behavior and performance. 
We also sought to uncover the mechanisms through which generalized trust operates and proposed two candidates. The first is commitment, by which generalized trust enhances loyalty to existing exchange partners. The second is adjustment, by which exchange partners are better able to mutually adjust to changing circumstances. We found support for an adjustment mechanism because, during the economic downturn, firms in high generalized trust regions benefited from external sourcing to a greater extent than firms in low generalized trust regions did. However, a direct test of a commitment mechanism was not supported because, during the economic downturn, firms in high generalized trust regions reduced external sourcing to a similar extent as firms in low generalized trust regions did. However, we would suggest future research to not fully discard commitment just yet because some indirect evidence suggests that it may play a role.

We highlight two contributions to the literature on interorganizational relationships. The first contribution is the shift from trust that is specific to another party to trust that is not specific to another party. Existing research has focused extensively on specific, or dyadic, trust (for a meta-analysis, see Connelly et al. 2018). In contrast, this study explores nonspecific, or generalized, trust. This generalized perspective allows us to explore different facets of organizational behavior: (1) Generalized trust affects a firm's portfolio of relationships; and (2) generalized trust accounts for differences between firms located in different regions. Neither of these predictions can be derived from research on dyadic trust because (1) dyadic trust concerns a single relationship; and (2) dyadic trust attributes differences to the specifics of the dyad, and not to the specifics of a region.

Furthermore, a shift from dyadic to generalized trust raises questions about the nature of trust itself. Conceptual models on the evolution of dyadic trust in interorganizational relationships suggest that trust takes time to build and takes a hit when the other party behaves in untrustworthy ways (e.g., Shapiro et al. 1992, Lewicki and Bunker 1995, and Schilke and Cook 2013). The underlying idea is that trust adjusts, reactively or proactively, to a level that is based on the level of the other party's trustworthiness (Stevens et al. 2015). Thus, this type of trust can be described as the consequences a trust decision has for the anticipated benefits and costs in the relationships. In contrast, generalized trust is often described as a social norm, which is passed down from one generation to the next (Uslaner 2008, Algan and Cahuc 2010). For this type of trust, a trust decision is not necessarily based on the anticipated benefits of costs in a given situation, but, rather, on whether it is deemed appropriate to trust in that situation.
The view of generalized trust as a social norm has several further implications. First, because it is stable, it may act as a reservoir of goodwill during an economic downturn. Second, because it is partneragnostic, it may become a self-fulfilling prophecy. One party's trusting action may lead the other party to reciprocate with a trustworthy behavior (Gulati et al. 1994, Pillutla et al. 2003, Vanneste 2016). Johnson and Mislin's (2011) meta-analysis lends support to this mechanism; their review of 137 trust games indicated that the proportion of money sent (a trusting action) increased the proportion of money returned (trustworthy behavior). Third, this reciprocity mechanism suggests an interplay between generalized and dyadic trust. An exciting area for future research is to understand more about this interplay (Ertug et al. 2013).

A second contribution to the literature on interorganizational relationships is that we seek to understand the role of generalized trust on performance for internal and external sourcing simultaneously. The vast majority of existing work has explored the effect of trust on performance for either internal (for metaanalyses, see Dirks and Ferrin 2002, Colquitt et al. 2007, and De Jong et al. 2016) or external organizing (for meta-analyses, see Cao and Lumineau 2015, Krishnan et al. 2016, and Connelly et al. 2018), but not both (for an exception focusing on dyadic trust, see Gulati and Nickerson 2008). One insight we get from simultaneously studying both governance modes is that even if generalized trust enhances firm performance, its benefits depend on the degree of external versus internal sourcing and the prevailing economic conditions. Specifically, in an economic downturn, generalized trust seems to especially benefit firms with a high degree of external sourcing. Thus, the boundary conditions on the benefits of generalized trust depend on the preferred governance mode firms use.

We note the following limitations of our study that we believe may also be opportunities for future research. First, from a data standpoint, we do not know the locations of external suppliers that our focal firms use. Like many dyadic trust studies, we developed a generalized trust perspective by focusing on one firm in the portfolio. As a result, we gained a deeper understanding of the role of the buying firm, but are unable to shed much light on that of the external suppliers. Furthermore, we cannot uncover how the buying firm's choices interact with those of the external suppliers. To explore these issues further, an opportunity exists to combine data on dyadic relationships with the type of geographic data that we have exploited.

Second, from a methodological standpoint, the interactions among selecting a relationship, performance, and trust make it difficult to disentangle their 
effects on each other. Although our study is certainly not free of endogeneity concerns, generalized trust is plausibly exogenous to both the selection and performance of partners. Thus, the relationship between regional characteristics and external sourcing or performance is likely complex, and we are able to highlight only one facet of that relationship. Future work could explore an exogenous shock different than ours or focus on firms relocating.

We highlight several additional opportunities for future research that emerge directly from this study. First, our approach was to understand the role of generalized trust in performance differences before and during an economic downturn, holding constant the locations of SMEs. Future work may study whether generalized trust affects the geographic location of firms across regions. For example, industries differ in their mean level of external sourcing. Our findings suggest that external sourcing is more beneficial in some regions than in others. Hence, generalized trust may well influence the geographic location of industries and their relative prosperity in some regions compared with others. More generally, high generalized trust regions with buying firms keen to rely on the market may provide fertile settling grounds for suppliers. Thus, it could well be that buying firms are not only keener to rely on external suppliers, but also face more of them in local proximity. It would be interesting to analyze these pathways separately and understand how they reinforce each other.

Second, to obtain firms located in a single region, we focused on SMEs. Our theoretical arguments are not, however, based on firm size. Hence, we may expect a similar pattern of results for large firms, if located in a single region. Future work may investigate whether that is indeed the case. However, large firms may well extend across multiple regions, which suggests opportunities for future research. One approach is to focus on headquarters' location. That location becomes more dominant to the extent that external sourcing decisions are made at the headquarters and less dominant if decisions are made locally (Bidwell 2012). The work on generalized trust and decentralization (Bloom et al. 2012, Cingano and Pinotti 2016, Gur and Bjørnskov 2017, Van Hoorn 2017) suggests an intriguing twist. Such work has found that firms in high-trust regions decentralize more. In that spirit, headquarters would matter more for external sourcing if they were located in a low, rather than in a high, generalized trust region.

Third, we argued that generalized trust matters for all suppliers, including those from different regions. However, we cannot empirically verify whether it matters more for suppliers from some regions than others (because supplier location is unknown). Future work may study the role of generalized trust in the supplier region. It would be especially interesting to consider when locations are mismatched: The focal firm is located in a high generalized trust region and the supplier in a low generalized trust region, or vice versa. Those instances would give us the opportunity to study trust asymmetries. Recent work has started exploring trust asymmetries in the context of dyadic trust (McEvily et al. 2017, Graebner et al. 2020). An opportunity exists to do likewise for generalized trust.

Fourth, and more generally, we sought to bring a generalized trust perspective to the study of interorganizational relationships. A rich literature exists on the importance of trust for interorganizational relationships from a dyadic perspective. More research is needed to understand the interplay of these two perspectives. Here, we propose three possible relationships between generalized trust and dyadic trust that future research can unpack with granular data at the dyad and field level. First, generalized trust may enhance dyadic trust, especially at the early stages of a relationship. Generalized trust encourages firms to reach out to new business partners and to take trusting actions, even if little is known about the other. To the extent that dyadic trust benefits from trusting actions and their reciprocations (Vanneste 2016), generalized trust may act as a catalyst for dyadic trust. Yet, we must also note that generalized trust may lead an organization to build dyadic trust with a partner, who may later reveal itself as unworthy of that trust. Second, dyadic trust may enhance generalized trust. It is suggested that civic engagement may lead to generalized trust because interacting with different others may make us more trusting of unknown others (Putnam 2000). In the same spirit, having trust in specific exchange partners may make us more trusting of new partners. Third, generalized trust and dyadic trust will jointly influence exchange performance, but how it does so is yet unclear. If they are substitutes, then increasing dyadic trust is less valuable in the presence than absence of generalized trust (cf. Milgrom and Roberts 1990). In this case, a relationship may perform well, as long as one trust type is present. A relationship needs trusting actions and cooperative norms, but their origins are less important. If they are complements, then increasing dyadic trust is more valuable in the presence than absence of generalized trust. In this case, a relationship may perform well only if both types of trust are present. This situation is more likely if generalized trust and dyadic trust differ in not only their origins, but also their consequences.

\section{Acknowledgments}

The authors thank the senior editor, Matthew Bidwell, and three anonymous reviewers for their valuable comments and suggestions throughout the review process. The authors are grateful for outstanding research 
assistance from Caroline Koekkoek; for the help of Paige Kemp, Qing Ye, and James Zeitler; and for comments from Dennis Campbell, Kenny Ching, Julien Clement, Isabel Fernandez-Mateo, Laura Kerrigan, Sunkee Lee, Steven Lui, Arianna Marchetti, Marco Minervini, Phanish Puranam, Prateek Raj, and Suraj Srinivasan. The authors also wish to recognize seminar participants at Bayes Business School, the Bocconi University, HEC Paris, UNSW Sydney, the University of Southern Denmark, the University of St. Gallen, and the UCL School of Management reading group.

\section{Appendix: Selection of Control Variables}

The double-selection method proceeds in three steps. First, select the control variables that predict the dependent variable (e.g., external sourcing) to find potential confounds and to reduce the residual variance. Second, select the control variables that predict the key independent variable (e.g., generalized trust) to minimize omitted variable bias. Third, estimate the effect of the key independent variable on the dependent variable, while using as control variables the union of variables selected in steps 1 and 2 . The unique feature of this selection procedure is step 2, which explains the name double-selection procedure. Other well-known selection procedures-for example, keeping only the significant predictors of the dependent variable or using forward (or backward) stepwise selection-perform only step 1. Ignoring step 2, however, can lead to omitted-variable bias (Belloni et al. 2014a).

To estimate steps 1 and 2, we use a LASSO (least absolute shrinkage and selection operator) estimator (Tibshirani 1996; for an introduction to LASSO, see James et al. 2013, chapter 6):

$$
\hat{\beta}^{\text {LASSO }}=\underset{\beta}{\arg \min }\left\{\frac{1}{2} \sum_{i=1}^{N}\left(y_{i}-\beta_{0}-\sum_{j=1}^{p} x_{i j} \beta_{j}\right)^{2}+\lambda \sum_{j=1}^{p}\left|\beta_{j}\right|\right\} .
$$

The LASSO estimator is equivalent to the ordinary least squares (OLS) estimator with a penalty $\left(\lambda \sum_{j=1}^{p}\left|\beta_{j}\right| ; \hat{\beta}^{\text {OLS }}\right.$ is when $\lambda=0)$. Because of that penalty, the coefficients are smaller in a LASSO estimation than in an OLS estimation. Furthermore, because of this particular penalty, the LASSO coefficients will be exactly zero for some variables. It is this property that enables the selection of variables. We determine $\lambda$ using $k=10$-fold cross-validation. Cross-validation assesses to what extent a model generalizes to data not used for estimating that model. The value for $\lambda$ is chosen so that the LASSO does not overfit on the data used for estimation. For step 3, we use OLS (i.e., so-called postLASSO) (Belloni et al. 2014b).

We implement the double-selection procedure once for the external sourcing regression (see part A of Table A3 in the online appendix) and once for the performance regression (part $B$ of the table). For the external sourcing regression, in step 1A (with external sourcing as the dependent variable), we consider the following flexible specification: all regional variables from Table A1 (see the online appendix) as a third-degree polynomial (i.e., $x+x^{2}+x^{3}$ ) (Belloni et al. 2014b), plus interactions between country and all company variables (from Table A2 in the online appendix) as a third-degree polynomial. Of the resulting 364 variables, the LASSO selects 77 . The specification in step 2A (with generalized trust as the dependent variable) is based on all regional variables as a third-degree polynomial. The number of variables selected is nine out of 66 . The union of variables selected in steps $1 \mathrm{~A}$ and $2 \mathrm{~A}$ yield 86 independent variables for step 3A. One technical detail is that variables can be excluded from the penalty function in order to ensure their retention (Belloni et al. 2014b). We retain the variable operating expenses (ln) to help interpret changes in the dependent variable. Furthermore, because generalized trust is the variable of interest, it is also excluded from the penalty function and therefore always retained. Another technical detail is that we use a fixed-effects regression in step 3A. We therefore demean the data prior to variable selection in step 1A (by country and industry) and in step 2A (by country).

For the performance regression, in step $1 \mathrm{~B}$ (with $R O A$ as the dependent variable), we use all regional variables as a third-degree polynomial plus interactions between country and all company variables as a third-degree polynomial. ${ }^{19}$ Out of 287 variables, the LASSO selects 145 . In step $2 \mathrm{~B}$, the goal is to find predictors for external sourcing and generalized trust, which we already did for the external sourcing regression. Hence, we take the variables selected in steps $1 \mathrm{~A}$ and $2 \mathrm{~A}$. For step $3 \mathrm{~B}$, combining those steps yields 166 independent variables. Note that this number excludes variables dropped because of firm and year fixed effects (e.g., size, legal_form, and their derived variables). As before, we retain the variables that are important for interpreting the results, including operating expenses $(\ln )$, total assets $(\ln )$, and operating revenue $(\ln )$ (see Table A3 in the online appendix). We also demean the data before variable selection in step 1B (by firm and year).

\section{Endnotes}

${ }^{1}$ In a trust game, party A must decide what portion of a financial endowment to send to party B. Any money sent will increase during transit, and party B must then decide what portion of that increased sum to return to party A (Berg et al. 1995). The funds sent by party $A$ are a proxy for trust and the funds returned by party B proxy for trustworthiness.

${ }^{2}$ One exception is the United States, where generalized trust consistently declined from 1960 to 2000 (Putnam 2000).

${ }^{3}$ An additional driver of increased usage of external sourcing in high generalized trust regions is that suppliers may choose to locate near potential buyers. In that case, firms in high generalized trust regions not only have a greater willingness to rely on external parties, but also face more options for doing so. In the absence of information on suppliers' locations, we cannot directly test this mechanism.

${ }^{4}$ The relationship between generalized trust and civic engagement is suggested to be reciprocal: Generalized trust leads to civic engagement, and civic engagement leads to generalized trust (Putnam 2000).

${ }^{5}$ See http://www.europeanvaluesstudy.eu

${ }^{6}$ See http://ec.europa.eu/eurostat/web/regions

${ }^{7}$ Regions with fewer than 30 respondents in either survey are excluded. The observed correlation $\left(r_{o b s}\right)$ is attenuated by any measurement error. The population correlation $\left(r_{p o p}\right)$ is related as 
follows: $r_{o b s}=a b r_{p o p}$, where $a$ and $b$ are the square root of the reliabilities of the generalized trust measurements (Hunter and Schmidt 2004). This formula yields $r_{p o p}=0.87$ (for reliabilities of $0.95)$ and $r_{\text {pop }}=0.92$ (for reliabilities of 0.90 ).

${ }^{8}$ The NUTS classification is updated every three or four years, yet there are seldom any changes at the NUTS2 level. The EVS uses NUTS 2006, and Eurostat uses NUTS 2010 for data related to those years. Four regions underwent minor boundary changes, and two regions merged. As a robustness check, we exclude those regions; results are similar to those reported here.

${ }^{9}$ We calculated the measure's standard error as follows. A response is a draw from a Bernoulli distribution with the probability of one $(=p)$ specific by region. A single response has variance $p(1-p)$. The measure's standard error based on $n$ responses is then the square root of $p(1-p) / n$.

${ }^{10}$ Annual Report on European SMEs 2015/2016, SME recovery continues-SME Performance Review 2015/2016, European Commission.

${ }^{11}$ Commission Recommendation of 6 May 2003, concerning the definition of micro, small, and medium-sized enterprises (2003/ 361/EC), Official Journal of the European Union, L 124/36, May 20, 2003.

${ }^{12}$ See http://ec.europa.eu/eurostat/web/nuts/correspondencetables/postcodes-and-nuts

${ }^{13}$ See http://ec.europa.eu/eurostat/web/nuts/local-administrativeunits

${ }^{14}$ We verify the calculated materials and services expenses by way of a direct measure of "materials-only" expenses, which is provided by Amadeus for about $77 \%$ of the sample. This materials-only measure is strongly correlated $(r=0.89)$ with the calculations and is smaller in $98 \%$ of the observations (because it excludes services).

${ }^{15}$ Lagging the independent variables would require dropping observations from the year 2006, making it impossible to test the economic-downturn hypotheses. Hence, the independent variables are not lagged. We investigated the difference between lagging and not lagging the independent variables for the years 2007-2010. The effect of generalized trust on external sourcing is unaffected $(b=$ $0.032(p=0.01)$ with lagging and $b=0.034(p=0.01)$ without lagging). For the table with regression results, see the online appendix.

${ }^{16}$ https://group.bnpparibas/en/press-release/bnp-paribas-invest ment-partners-temporaly-suspends-calculation-net-asset-funds-parvestdynamic-abs-bnp-paribas-abs-euribor-bnp-paribas-abs-eonia

${ }^{17}$ https://ec.europa.eu/eurostat/

${ }^{18}$ The difference in results with and without firm fixed effects remains when restricting the sample to firms observed in all years. Hence, differential entry and exit cannot account for this difference. Furthermore, across the specifications, the restricted sample yields results similar to those reported as the main results.

${ }^{19}$ For comparison purposes, we use the same model specification when reporting the performance results for both ROA and ROS.

\section{References}

Accounting Standards Steering Committee (1975) The Corporate Report: A Discussion Paper Published for Comment. Report, Accounting Standards Steering Committee of the Institute of Chartered Accountants in England and Wales, London.

Aghion P, Bloom N, Lucking B, Sadun R, Van Reenen J (2021) Turbulence, firm decentralization, and growth in bad times. Amer. Econom. J. Appl. Econom. 13(1):133-169.

Algan Y, Cahuc P (2010) Inherited trust and growth. Amer. Econom. Rev. 100(5):2060-2092.
Algan Y, Cahuc P (2013) Trust and growth. Annu. Rev. Econom. 5: 521-549.

Angrist JD, Pischke JS (2008) Mostly Harmless Econometrics: An Empiricist's Companion (Princeton University Press, Princeton, NJ).

Arrow K (1974) The Limits of Organizations (Norton, New York).

Belloni A, Chernozhukov V, Hansen C (2014a) Inference on treatment effects after selection among high-dimensional controls. Rev. Econom. Stud. 81(2):608-650.

Belloni A, Chernozhukov V, Hansen C (2014b) High-dimensional methods and inference on structural and treatment effects. J. Econom. Perspect. 28(2):29-50.

Berg J, Dickhaut J, McCabe K (1995) Trust, reciprocity, and social history. Games Econom. Behav. 10(1):122-142.

Bidwell M (2010) Problems deciding: How the structure of make-orbuy decisions leads to transaction misalignment. Organ. Sci. 21 (2):362-379.

Bidwell M (2012) Politics and firm boundaries: How organizational structure, group interests, and resources affect outsourcing. Organ. Sci. 23(6):1622-1642

Bjørnskov C (2007) Determinants of generalized trust: A crosscountry comparison. Public Choice 130(1):1-21.

Bloom N, Sadun R, Van Reenen J (2012) The organization of firms across countries. Quart. J. Econom. 127(4):1663-1705.

Bradach JL, Eccles RG (1989) Price, authority, and trust: From ideal types to plural forms. Annu. Rev. Sociol. 15(1):97-118.

Bradley SW, Aldrich H, Shepherd DA, Wiklund J (2011) Resources, environmental change, and survival: Asymmetric paths of young independent and subsidiary organizations. Strategic Management J. 32(5):486-509.

Brynjolfsson E, Hitt LM (2003) Computing productivity: Firm-level evidence. Rev. Econom. Statist. 85(4):793-808.

Bun MJ, Harrison TD (2019) OLS and IV estimation of regression models including endogenous interaction terms. Econometric Rev. 38(7):814-827.

Cao Z, Lumineau F (2015) Revisiting the interplay between contractual and relational governance: A qualitative and meta-analytic investigation. J. Oper. Management 33-34:15-42.

Chandler AD (1962) Strategy and Structure: Chapters in the History of the Industrial Enterprise (MIT Press, Cambridge, MA).

Cingano F, Pinotti P (2016) Trust, firm organization, and the pattern of comparative advantage. J. Internat. Econom. 100:1-13.

Coleman JS (1990) Foundations of Social Theory (Belknap Press, Cambridge, MA).

Colquitt JA, Scott BA, LePine JA (2007) Trust, trustworthiness, and trust propensity: A meta-analytic test of their unique relationships with risk taking and job performance. J. Appl. Psych. 92 (4):909-927.

Connelly BL, Crook TR, Combs JG, Ketchen DJ Jr, Aguinis H (2018) Competence- and integrity-based trust in interorganizational relationships: Which matters more? J. Management 44(3):919-945.

Cook KS, Emerson RM (1978) Power, equity and commitment in exchange networks. Amer. Sociol. Rev. 43(5):721-739.

Cuypers I, Hennart JF, Silverman B, Ertug G (2021) Transaction cost theory: Past progress, current challenges, and suggestions for the future. Acad. Management Ann. 15(1):111-150.

David RJ, Han SK (2004) A systematic assessment of the empirical support for transaction cost economics. Strategic Management J. 25(1):39-58.

De Jong BA, Dirks KT, Gillespie N (2016) Trust and team performance: A meta-analysis of main effects, moderators, and covariates. J. Appl. Psych. 101(8):1134-1150.

Dirks KT, Ferrin DL (2002) Trust in leadership: Meta-analytic findings and implications for research and practice. J. Appl. Psych. 87(4):611-628.

Durante R (2010) Risk, cooperation and the economic origins of social trust: An empirical investigation. Amer. Econom. Assoc. Annual Meeting Papers (Atlanta, GA), 1-45. 
Dussauge P, Garrette B (1999) Cooperative Strategy: Competing Successfully Through Alliances (John Wiley and Sons, Chichester, UK).

Dyer JH (1996) Specialized supplier networks as a source of competitive advantage: Evidence from the auto industry. Strategic Management J. 17(4):271-291.

Dyer JH, Singh H (1998) The relational view: Cooperative strategy and sources of interorganizational competitive advantage. Acad. Management Rev. 23(4):660-679.

Dyer JH, Singh H, Hesterly WS (2018) The relational view revisited: A dynamic perspective on value creation and value capture. Strategic Management J. 39(12):3140-3162.

Edström A, Galbraith JR (1977) Transfer of managers as a coordination and control strategy in multinational organizations. Admin. Sci. Quart. 22(2):248-263.

Ertug G, Cuypers IR, Noorderhaven NG, Bensaou BM (2013) Trust between international joint venture partners: Effects of home countries. J. Internat. Bus. Stud. 44(3):263-282.

Eurostat (2011) Regions in the European Union: Nomenclature of territorial units for statistics NUTS 2010/EU-27. Methodologies \& Working Papers, Eurostat, Luxembourg.

EVS (2016) European Values Study 2008: Integrated Dataset (EVS 2008). ZA4800 Datafile Version 4.0.0, GESIS Data Archive, Cologne, Germany.

EVS (2020) European Values Study 2017: Integrated Dataset (EVS 2017). ZA7500 Datafile Version 3.0.0, , GESIS Data Archive, Cologne, Germany.

Fehr E, Fischbacher U, Von Rosenbladt B, Schupp J, Wagner GG (2002) A nation-wide laboratory: Examining trust and trustworthiness by integrating behavioral experiments into representative surveys. J. Appl. Soc. Sci. Stud. 122(4):519-542.

Fukuyama F (1995) Trust: The Social Virtues and the Creation of Prosperity (Free Press, New York).

Galbraith JR (1973) Designing Complex Organizations (Addison-Wesley, Reading, MA).

Gargiulo M, Ertug G (2006) The dark side of trust. Bachmann R, Zaheer A, eds. Handbook of Trust Research (Edward Elgar, Cheltenham, UK), 165-186.

Geyskens I, Steenkamp JBE, Kumar N (2006) Make, buy, or ally: A transaction cost theory meta-analysis. Acad. Management J. 49(3): 519-543.

Gibbons R (2003) Team theory, garbage cans, and real organizations: Some history and prospects of economic research on decisionmaking in organizations. Indust. Corporate Change 12(4):753-787.

Glaeser EL, Laibson DI, Scheinkman JA, Soutter CL (2000) Measuring trust. Quart. J. Econom. 115(3):811-846.

Graebner ME, Lumineau F, Fudge Kamal D (2020) Unrequited: Asymmetry in interorganizational trust. Strategic Organ. 18(2): 362-374.

Grossman SJ, Hart OD (1986) The costs and benefits of ownership: A theory of vertical and lateral integration. J. Polit. Econom. 94 (4):691-719.

Guiso L, Sapienza P, Zingales L (2004) The role of social capital in financial development. Amer. Econom. Rev. 94(3):526-556.

Guiso L, Sapienza P, Zingales L (2008) Trusting the stock market. J. Finance. 63(6):2557-2600.

Gulati R (1995a) Social structure and alliance formation patterns: A longitudinal analysis. Admin. Sci. Quart. 40(4):619-652.

Gulati R (1995b) Does familiarity breed trust? The implications of repeated ties for contractual choice in alliances. Acad. Management J. 38(1):85-112.

Gulati R (1999) Network location and learning: The influence of network resources and firm capabilities on alliance formation. Strategic Management J. 20(5):397-420.

Gulati R, Higgins MC (2003) Which ties matter when? The contingent effects of interorganizational partnerships on IPO success. Strategic Management J. 24(2):127-144.
Gulati R, Nickerson JA (2008) Interorganizational trust, governance choice, and exchange performance. Organ. Sci. 19(5):688-708.

Gulati R, Khanna T, Nohria N (1994) Unilateral commitments and the importance of process in alliances. MIT Sloan Management Rev. 35(3):61-69.

Gulati R, Lawrence PR, Puranam P (2005) Adaptation in vertical relationships: Beyond incentive conflict. Strategic Management J. 26(5):415-440.

Gulati R, Nohria N, Wohlgezogen F (2010) Roaring out of recession. Harvard Bus. Rev. (March):63-69.

Gulati R, Nohria N, Zaheer A (2000) Strategic networks. Strategic Management J. 21(3):203-215.

Gur N, Bjørnskov C (2017) Trust and delegation: Theory and evidence. J. Comparative Econom. 45(3):644-657.

Holm HJ, Danielson A (2005) Tropic trust vs. Nordic trust: Experimental evidence from Tanzania and Sweden. Econom. J. 115 (503):505-532.

Holmström B (1982) Moral hazard in teams. Bell J. Econom. 13(2): 324-340.

Holmström B (1999) Managerial incentive problems: A dynamic perspective. Rev. Econom. Stud. 66(1):169-182.

Hunter JE, Schmidt FL (2004) Methods of Meta-Analysis: Correcting Error and Bias in Research Findings (Sage, Thousand Oaks, CA).

Jacobides MG (2005) Industry change through vertical disintegration: How and why markets emerged in mortgage banking. Acad. Management J. 48(3):465-498.

James G, Witten D, Hastie T, Tibshirani R (2013) An Introduction to Statistical Learning (Springer, New York).

Johnson ND, Mislin AA (2011) Trust games: A meta-analysis. J. Econom. Psych. 32(5):865-889.

Johnson ND, Mislin A (2012) How much should we trust the World Values Survey trust question? Econom. Lett. 116(2):210-212.

Knack S, Keefer P (1997) Does social capital have an economic payoff? A cross-country investigation. Quart. J. Econom. 112(4): 1251-1288.

Kogut B, Zander U (1996) What firms do? Coordination, identity, and learning. Organ. Sci. 7(5):502-518.

Kramer RM (1999) Trust and distrust in organizations: Emerging perspectives, enduring questions. Annu. Rev. Psych. 50(1):569598.

Kretschmer T, Puranam P (2008) Integration through incentives within differentiated organizations. Organ. Sci. 19(6):860-875.

Krishnan R, Geyskens I, Steenkamp JBE (2016) The effectiveness of contractual and trust-based governance in strategic alliances under behavioral and environmental uncertainty. Strategic Management J. 37(12):2521-2542.

Lafontaine F, Slade M (2007) Vertical integration and firm boundaries: The evidence. J. Econom. Lit. 45(3):629-685.

Levinthal DA, Fichman M (1988) Dynamics of interorganizational attachments: Auditor-client relationships. Admin. Sci. Quart. 33 (3):345-369.

Lewicki RJ, Bunker BB (1995) Trust in relationships: A model of development and decline. Bunker BB, Rubin JZ, eds. Conflict, Cooperation and Justice (Jossey-Bass, San Francisco), 133-173.

Lieberman MB, Garcia-Castro R, Balasubramanian N (2017) Measuring value creation and appropriation in firms: The VCA model. Strategic Management J. 38(6):1193-1211.

March JG, Simon HA (1958) Organizations (Wiley, New York).

Mayer RC, Davis JH, Schoorman FD (1995) An integrative model of organizational trust. Acad. Management Rev. 20(3):709-734.

McEvily B, Zaheer A, Kamal DKF (2017) Mutual and exclusive: Dyadic sources of trust in interorganizational exchange. Organ. Sci. 28(1):74-92.

Milgrom P, Roberts J (1990) The economics of modern manufacturing: Technology, strategy, and organization. Amer. Econom. Rev. 80(3):511-528. 
Murray JY, Kotabe M (1999) Sourcing strategies of US service companies: A modified transaction-cost analysis. Strategic Management J. 20(9):791-809.

Nannestad P (2008) What have we learned about generalized trust if anything? Annu. Rev. Political Sci. 11:413-436.

Nizalova OY, Murtazashvili I (2016) Exogenous treatment and endogenous factors: Vanishing of omitted variable bias on the interaction term. J. Econom. Methods 5(1):71-77.

Pillutla MM, Malhotra D, Murnighan JK (2003) Attributions of trust and the calculus of reciprocity. J. Experment. Soc. Psych. 39(5): $448-455$.

Poppo L, Zenger T (2002) Do formal contracts and relational governance function as substitutes or complements? Strategic Management J. 23(8):707-725.

Puranam P, Vanneste BS (2009) Trust and governance: Untangling a tangled web. Acad. Management Rev. 34(1):11-31.

Puranam P, Alexy O, Reitzig M (2014) What's "new" about new forms of organizing? Acad. Management Rev. 39(2):162-180.

Putnam RD (1993) Making Democracy Work: Civic Traditions in Modern Italy (Princeton University Press, Princeton, NJ).

Putnam RD (2000) Bowling Alone: The Collapse and Revival of American Community (Simon and Schuster, New York).

Ring PS, Van de Ven AH (1994) Developmental processes of cooperative interorganizational relationships. Acad. Management Rev. 19(1):90-118.

Rothstein B (2000) Trust, social dilemmas and collective memories. J. Theoret. Politics 12(4):477-501.

Sako M, Helper S (1998) Determinants of trust in supplier relations: Evidence from the automotive industry in Japan and the United States. J. Econom. Behav. Organ. 34(3):387-417.

Santos FM, Eisenhardt KM (2005) Organizational boundaries and theories of organization. Organ. Sci. 16(5):491-508.

Sapienza P, Toldra-Simats A, Zingales L (2013) Understanding trust. Econom. J. 123(573):1313-1332.

Schilke O, Cook KS (2013) A cross-level process theory of trust development in interorganizational relationships. Strategic Organ. 11(3):281-303.

Schmitt H, Bartolini S, Van der Brug W, Van der Eijk C, Franklin M, Fuchs D, Toka G, Marsh M, Thomassen J (2009) European Election Study 2004, 2nd ed. ZA4566 Datafile Version 2.0.0, GESIS Data Archive, Cologne, Germany.

Shapiro DL, Sheppard BH, Cheraskin L (1992) Business on a handshake. Negotiation J. 8(4):365-377.

Simon HA (1951) A formal theory of the employment relationship. Econometrica 19(3):293-305.

Stevens M, MacDuffie JP, Helper S (2015) Reorienting and recalibrating inter-organizational relationships: Strategies for achieving optimal trust. Organ. Stud. 36(9):1237-1264.

Stinchcombe AL (1968) Constructing Social Theories (University of Chicago Press, Chicago).

Stolle D (2001) Clubs and congregations: The benefits of joining an association. Cook KS, ed., Trust in Society (Russell Sage Foundation, New York), 202-244.

Tabellini G (2010) Culture and institutions: Economic development in the regions of Europe. J. Eur. Econom. Assoc. 8(4):677-716.

Tibshirani R (1996) Regression shrinkage and selection via the lasso. J. Roy. Statist. Soc. B 58(1):267-288.

Turnbull P, Oliver N, Wilkinson B (1992) Buyer-supplier relations in the UK-automotive industry: Strategic implications of the Japanese manufacturing model. Strategic Management J. 13(2): 159-168.
Uslaner EM (2002) The Moral Foundations of Trust (Cambridge University Press, Cambridge, UK).

Uslaner EM (2008) Where you stand depends upon where your grandparents sat: The inheritability of generalized trust. Public Opinion Quart. 72(4):725-740.

Van Hoorn A (2017) Social trust, workplace organization, and the comparative advantage of nations. Oxford Econom. Papers 69(4): 897-917.

van Ingen E, Bekkers R (2015) Generalized trust through civic engagement? Evidence from five national panel studies. Political Psych. 36(3):277-294.

Van Mieghem JA (1999) Coordinating investment, production, and subcontracting. Management Sci. 45(7):954-971.

Vanneste BS (2016) From interpersonal to interorganisational trust: The role of indirect reciprocity. J. Trust Res. 6(1):7-36.

Vanneste BS (2017) How much do industry, corporation, and business matter, really? A meta-analysis. Strategy Sci. 2(2):121-139.

Vanneste BS, Frank DH (2014) Forgiveness in vertical relationships: Incentive and termination effects. Organ. Sci. 25(6):1807-1822.

Vanneste BS, Yoo OS (2020) Performance of trust-based governance. J. Organ. Design 9(14):1-28.

Vanneste BS, Puranam P, Kretschmer T (2014) Trust over time in exchange relationships: Meta-analysis and theory. Strategic Management J. 35(12):1891-1902.

Van Weele AJ (2014) Purchasing and Supply Chain Management: Analysis, Strategy, Planning and Practice, 6th ed. (Cengage Learning EMEA, Hampshire, UK).

Williamson OE (1975) Markets and Hierarchies-Analysis and Antitrust Implications (The Free Press, New York).

Williamson OE (1985) The Economic Institutions of Capitalism (The Free Press, New York).

Williamson OE (1991) Comparative economic organization: The analysis of discrete structural alternatives. Admin. Sci. Quart. 36 (2):269-296.

Withers MC, Certo ST, Semadeni M (2014) Examining the influence of endogeneity when testing interactions. Strategic Management Soc. Annual Conf., Madrid.

Zaheer A, Venkatraman N (1995) Relational governance as an interorganizational strategy: An empirical test of the role of trust in economic exchange. Strategic Management J. 16(5):373-392.

Zaheer A, McEvily B, Perrone V (1998) Does trust matter? Exploring the effects of interorganizational and interpersonal trust on performance. Organ. Sci. 9(2):141-159.

Bart S. Vanneste is associate professor of strategy at the UCL School of Management, University College London. He received his $\mathrm{PhD}$ in strategic and international management from the London Business School. His research interests include trust, interorganizational relationships, and corporate strategy, with a particular emphasis on the role of artificial intelligence and machine learning.

Ranjay Gulati is the Paul R. Lawrence MBA Class of 1942 Professor of Business Administration at the Harvard Business School. He received his $\mathrm{PhD}$ in organizational behavior from Harvard University. His research interests include the dynamics of social networks with a focus on the antecedents and consequences of social structure on economic exchange relationships between firms. 